\title{
The Value Assimilation Effect Between University Professors and Their Students in the Classroom
}

\author{
Glory Emmanuel-Aviña ${ }^{1,2, *} \&$ Harold D. Delaney ${ }^{2}$ \\ ${ }^{1}$ Sandia National Laboratories, USA \\ ${ }^{2}$ The University of New Mexico, USA \\ *Correspondence: Sandia National Laboratories, 7011 East Avenue, Livermore, CA, 94550, USA. Tel: \\ 1-925.294.2478. E-mail: gremman@sandia.gov
}

Received: January 18, 2018

Accepted: February 28, 2018 Online Published: April 24, 2018

doi:10.5430/jct.v7n1p158

URL: https://doi.org/10.5430/jct.v7n1p158

\begin{abstract}
In the clinical, therapy context, it has consistently been found that while therapists' value systems are stable, clients' values are less stable and become congruent with their therapists' values over the course of psychotherapy (e.g., Schwehn \& Schau, 1999). This phenomenon is termed the Value Assimilation Effect (VAE). This study examined if the VAE occurs in the university context between professors and students, that is if students' values assimilate to their professors. The current study tested three main hypotheses: 1) students demonstrate value change over time while professors' values remain relatively stable over time; 2) students' attributes influence value change; and 3) students assimilate to their professor's values. In a sample of 20 classrooms, 14 professors, and 414 students, it was found that students' values did change over time, both for values-bases classes and for non-values based classes. Students' attributes, specifically their initial commitment to values and religious commitment, were predictive of value change with those more committed to values reporting less value change over the semester. Students were found to assimilate their values to their professor's values. This was influenced by class type (values versus non-values based) and students' belief in their professor's ability to teach. Unexpectedly, professors' impact on students' religiosity was the most consistent and robust finding in this study. The magnitude and direction of change in students' values were influenced by their professor's level of religiosity. The benefits and concerns of value assimilation are also discussed.
\end{abstract}

Keywords: values, value assimilation effect, professors, university students, religiosity

\section{Introduction}

\subsection{Power Differential in Academic Settings}

Values have been an area of high interest for social scientists because of the insight they provide into higher-level cognitions and the influence they have on decision-making and behavior. Past and current psychological research has endeavored to define values and to decipher how they may be measured. The literature also provides a deeper understanding of how values are formed, their resiliency as well as vulnerability, and different settings where values are manifested in both positive and negative ways. One factor is the presence of a power differential. An individual or group associated with a lower status may be influenced to alter their values so that they are more closely aligned to their superior. In the current study, focus is directed to the academic setting where the values of university students are found to be influenced by the classroom context, and, more specifically, their professors. The current study investigates if the values of students are influenced in the academic setting and what aspects of the educational environment are key contributors. Prior to describing the details of the current study, a concise overview of the value literature is presented. (See Emmanuel-Aviña \& Delaney (2014) for a more thorough literature review.)

\subsection{How Past and Current Literature Defines Values}

A single value is defined as an enduring belief where a specific mode of conduct or an end-state of existence is preferable to a converse mode of conduct or end-state of existence (Rokeach, 1973). A value has been defined as internalized cognitive structure that guides decision making by establishing basic principles of right and wrong, a sense of priorities, meaning, and patterns (Oyserman, 2015). Although it is believed that values are taught and 
learned in isolation from other values in an absolute manner, a single value does not often operate in isolation but is rather integrated with other similar values to create a value system (Schwartz, 2017; Seligman \& Katz, 1996). It is important to distinguish between a value and a value system because it is rare for an individual to operate using a single value and even rarer for that value to be consistently and equally applied to every situation. A value system is a cluster of individual values that are organized along a continuum of relative importance to facilitate a preferable mode of conduct or end-state (Rokeach, 1973). Systems of values demonstrate that there is a complexity to the nature of values. Individuals employ values with incredible versatility, guided by multiple, dynamic clusters of values that vary across time and display them differently to the self, friends, acquaintances, family, and strangers. Historically, values have been defined as "an individual's concept of a transituational [terminal, instrumental] goal, that expresses [individualistic, collectivist, both] interests concerned with a [enjoyment, security...maturity] motivational domain and evaluated on a range of importance [very important to unimportant] as a guiding principle in his/her life" (Schwartz \& Bilsky, 1987, p. 553). More recent descriptions categorize values into internal perspective and external perspective. The internal perspective describes values as having a unique role in evaluating the psychological functioning of humans; external perspective of values is how humans learn what is important through social interaction within a culture to determine which values are promoted and discouraged within that cohort (Cieciuch \& Schwartz, 2017).

Rokeach categorized values into two categories: instrumental and terminal values. Instrumental values are core to the individual and considered to be permanent in nature (1973). Examples include honesty, integrity, and creativity. There are two kinds of instrumental values: moral values and competence values. Moral values only refer to those that have an interpersonal focus and arouse emotions of guilt, conscience, or conviction when violated. Competence values are related to how one feels when they perceive themselves to be personally inadequate and as if their intelligence, logical reasoning, and/or imaginative abilities have been undermined. With moral values, the feelings are related to wrongdoing while with competence the feelings are associated with personal downfall. Terminal values are based on desired states, objectives that one attempts to work towards. Examples include self-respect, financial security, and inner harmony. There are two types of terminal values: personal and social. Personal values are end-states that are centered on the self, such as salvation and peace, whereas social values focus on the collective world around the individual through values such as justice and brotherhood. Through this categorization of values, Rokeach (1973) developed a framework where terminal and instrumental values are ranked relative to each other by an individual and used as an internal reference to develop opinions, beliefs, and attitudes. Furthermore, by knowing an individual's values, it is possible that one could predict behavior, ranging from political affiliation to religious beliefs, but this relationship is noisy and complicated (Cieciuch, 2017, Rokeach, 1973). This led researchers to conduct experiments in a variety of domains where they influenced values and measured the change in opinion and behavior. Examples of domains in which values have been investigated include but are not limited to: work values (Kuron, Lyons, Schweitz, \& Ng, 2017); consumer values (Park, Kim, Kwon, 2017; Sheth, Newman, \& Gross, 1991); environmental science (Browning et al., 2017; Stern, 2000); neuroscience research (Sugrue, Corrado, \& Newsome, 2004); and academia (Little, Gaier, \& Spoutz, 2018; Astin, 1993).

\subsection{Values in the Academic Setting}

The academic setting is an appropriate context for value consideration and development. As stated by former Harvard president, "universities should be among the first to reaffirm the importance of basic values such as honesty, promise keeping, free expression, and nonviolence...to help students develop a strong set of moral standards" (Bok, 1990, p. 100). Academia also provides a context where students are forced to examine their own values and consider whether and why they are congruent or incongruent with what other individuals or groups in their cohort desire (Miller, 2018). Astin (2012) argued that it is futile to believe that liberal education is value-free; society is calling for values such as social responsibility, concern for others, empathy, and social responsibility to be qualities of higher education. A longitudinal study by Astin, Astin, and Lindholm (2011) found that students' undergraduate experiences are significantly enhanced when qualities such as caring and equanimity are developed over the course of their academic career.

\subsection{The Impact of a Power Differential on Values}

Individual and social change would be impossible if values were completely stable. In the same way, the continuity of human personality and society would be impossible if values were completely unstable. In clinical psychology research, a phenomenon entitled the Value Assimilation Effect (VAE) has been detected. It is a common belief in the profession that therapists' personal values should not interfere with therapy, but the question remains, "Can therapist values honestly be eliminated from therapy?" Psychologists have argued that the notion of keeping one's personal 
values out of therapy is not a feasible option. As Ingham and Love (1954) articulate, if a client and therapist are discussing issues over time which involve moral values, it is evident that the patient will have a concept of the therapist's personal opinions and values. The therapist's attitudes, whether intentional or not, about right and wrong, or good and bad, are likely to be particularly influential for the patient. Although clinicians in training are often taught to eliminate their values from their interaction with a client, the idea of implicit, unconscious value assimilation argues that value-free therapy is a misconception and unachievable. As Figure 1 illustrates, at the beginning of therapy the relationship between therapist and client values was moderately weak both for terminal values $(r=.33)$ and for instrumental values $(r=.36)$. However, by the end of therapy, the value congruence, or the relationship between therapist and client values, was very strong (terminal values, $r=.81$; instrumental values, $r$ $=.69$ ). The magnitude of change is substantial, with an increase in $r$ of .48 for terminal values, and of .36 for instrumental values. Subsequent review of the relevant empirical research has confirmed these findings (Beutler, 1981; Kessel \& McBrearty, 1967; Tjeltveit, 1986). Congruence between therapist and client of both terminal values (e.g., goals such as good family, job promotion) and instrumental values (e.g., personal traits such as honesty, perseverance) was stronger after therapy compared to before.

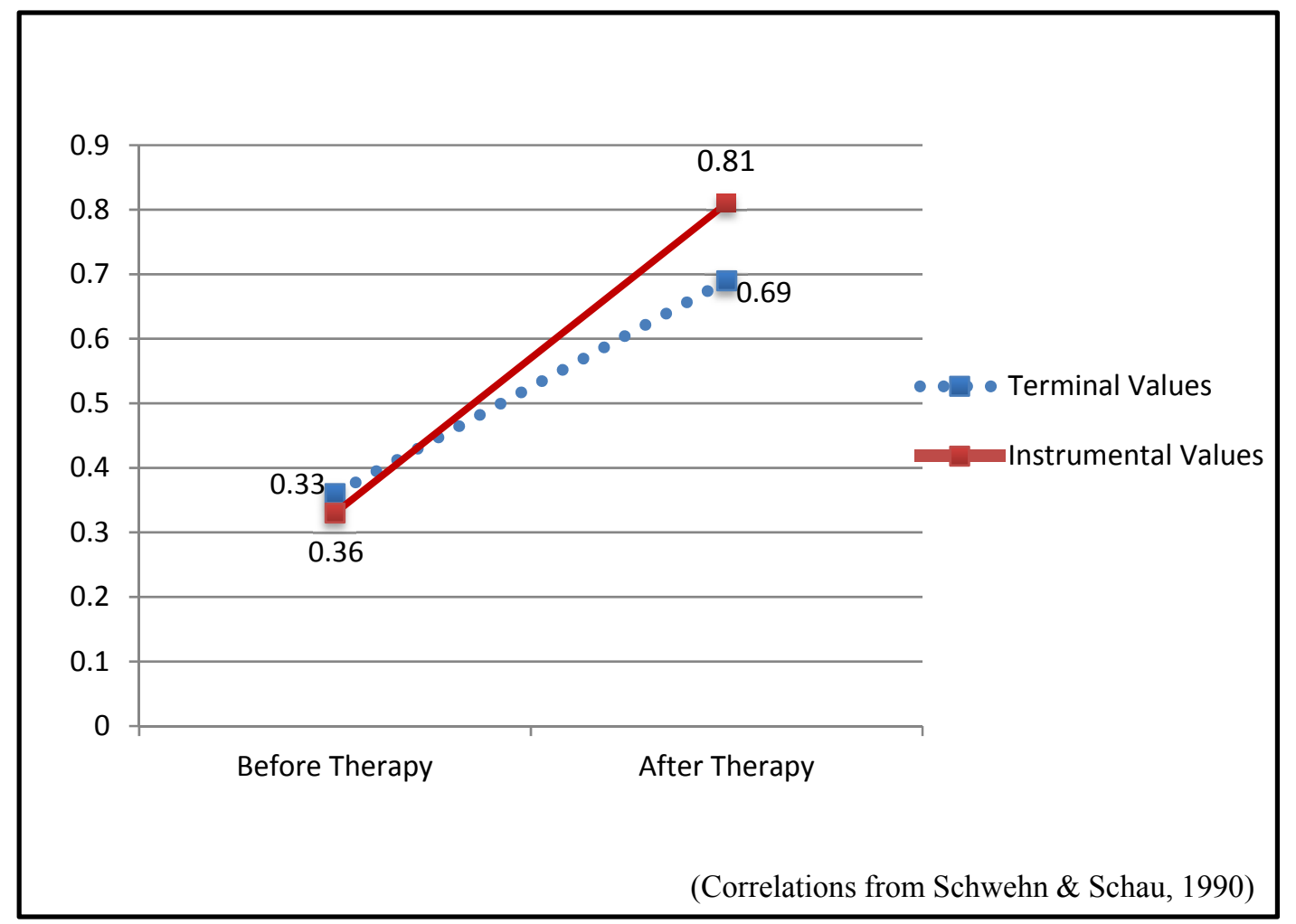

Figure 1. Illustration of the Value Assimilation Effect: Increase in Congruence between Therapist-Client Values over the Course of Therapy

In the academic environment, a power differential is present between the teacher and the students. As Hurt, Scott, and McCroskey (1978) argue, the teacher's role of power is always present and instills the control and facilitates the communication needed for students to learn in the classroom setting. The instructor's role has a power that entails the responsibility to know people and to be able to elicit performance and growth from them (Overbeck \& Park, 2001). McCroskey and Richmond (1983) explained that this power dynamic is critical for the teaching process as it provides the mechanism needed for students to be taught and influenced beyond their current level of intellect and maturity. A teacher's degree of power in the classroom is expected to lead to some form of change in students' value (McCroskey \& Richmond, 1983).

\subsection{Positive and Negative Effects on Values in Teaching}

\subsubsection{Potential Positive Effects}

The goal of a classroom setting should not be to indoctrinate professors' values to their students. The primary 
positive effect professors can have on their students' values is to provide a classroom setting where students can openly consider and anchor their own values in relation to their worldview by hearing the opinions of their professors and colleagues (Braskamp, Trautvetter, \& Ward, 2016). This enables students to actively engage in the formulation of their values and go through an anchoring process where beliefs are linked to their specific values or goals (Nelson, 1968). Astin (1977) reported on findings from longitudinal data of approximately 200,000 students and found that through involvement in the classroom, students develop a more positive self-image through stronger interpersonal and intellectual competence. Smith, Vicuña, and Emmanuel-Aviña (2015) discuss how professors have the opportunity to communicate the importance of meaning in life, having a sense of calling, and a spiritual worldview. Making the transition from high school to college, undergraduates may have never been in a context where they independently considered their own values. Whether college students remain true to the worldview they were reared in or alter their beliefs, the university setting provides students with the atmosphere and community to examine, consider, and dialogue about their beliefs, values, attitudes, faith, and other aspects related to worldview (Hindman, 2002).

\subsubsection{Potential Negative Effects}

As in clinical psychology when Rosenthal (1955) as well as Meehl and McClosky (1947) investigated value differences between client and therapists and found that therapists do not remain value-free even when they intend to do so, professors are also unlikely to keep their own personal values from influencing their teaching practices. The following is a list of terms, as presented in Tjeltveit (1986), that have been used to describe therapists: crypto-missionaries, hidden preachers, secular priesthood, indoctrination and brainwashing, form of persuasion, interpersonal influence, converted/conversion, and convergence. As reported by Astin (1977), undergraduates over time come to report more liberal political views and attitudes towards social issues, less interest in religiousness and altruism, and reduced value towards athletics, business, music, and status. Although these changes may be deemed by some to be positive, if they are transferred from professors to students without students' awareness, professors could be labeled with the same list of terms that therapists have been accused of. Teachers could be viewed as exploiting the power differential if students are implicitly, subconsciously acquiring their professors' values. Additionally, values may be transferred to specific groups of students due to their academic major, ethnic background, student group involvement, demographics, etc. Academic institutions may develop further prejudices and structural barriers to student groups if developing student values, such as creating a more just and equitable society, is not provided to the student body as a whole (Astin \& Astin, 2015).

\subsection{The Current Study}

Leveraging the established literature and methodologies on values, this research study examined if values of university students were influenced over a semester by the students' attributes, the professor, and the classroom environment. The overall aim was to quantitatively demonstrate that university students do experience a change in their values over a semester period and that they are influenced by their own initial values (their starting point), the nature of the class, and the values of their professor. This study specifically tested the following three hypotheses:

1) Students will demonstrate value change over time while professors' values will remain relatively stable over time.

2) Students' attributes will influence value change.

3) Students, especially those who have a positive experience in the class, may assimilate to professors' values.

\section{Method}

To investigate the presence of value change in the academic setting, professors and students nested in classrooms completed a self-report questionnaire on values and their classroom experience. Institutional Review Board (IRB) approval was first obtained and each participant provided written consent before data collection materials were presented. Professors and students at a public university located filled out the questionnaire during the first week of the semester and then again at the end of the semester. Data were analyzed to examine if participants' values changed over the semester and, if so, what factors contributed to the change.

Professors from two types of classes were contacted: 1) departments that have courses which discuss value-based topics were contacted: the Honors College, Psychology, and Education, and 2) departments that have courses which focus on facts and formulas: Computer Science, Statistics and Mathematics, Earth and Planetary Science, and Environmental Science. Fourteen professors agreed to be in the study along with one or two of their classes, for a total of 20 classes. 
Data collection occurred during the first and last week of the school semester. Research assistants visited the classrooms during the first week of class, introduced the study, and obtained consent from all participants willing to complete the questionnaire. All students were informed that their participation was voluntary, that their responses were anonymous, and that they could withdraw from the study at any time. Professors and students filled out the same questionnaire they filled out during the first week of class. Reliable and validated measures were used in this study: the Rokeach Value Survey (RVS, Rokeach, 1973); Goal, Social, and Mode Values Inventories (Braithwaite \& Law, 1985); and Values-in-Action (VIA; Park \& Peterson, 2006).

Statistical analyses were conducted to evaluate the data collected from professors and students in classrooms and test if value change and assimilation occurred. Analyses for each hypothesis were performed using IBM SPSS 22.0. Before analyses were conducted, data were screened for missing and erroneous data. Participants who did not complete the questionnaire twice were not used in analyses that looked at change over time. Data were also checked for missing data, assumptions of normality of distributions, homogeneity of variance, and multicollinearity. Analyses tested if there was a significant change in the mean for each subscale from Time 1 to Time 2 among professors and students, using a False Discovery Rate correction to control for experiment-wise alpha (Maxwell \& Delaney, 2004).

In regard to power and sample size, there was a big discrepancy between the number of professors in the study and the number of students. Because of the widely varying sample sizes of the two groups, there would be considerably less power to detect change in the professors than to detect change in the students; thus, estimates of effect size were also computed, anticipating that student's effect size would be larger than that of the professors. A within-subjects analysis was conducted to test if the professors' and students' values changed over time. Professor and student data were initially analyzed separately. For students, a between $\mathrm{x}$ within design was used to account for students being nested in classes. The different classes constituted levels of a random between-subject factor nested within the levels of a fixed between-subject factor of type of class (values-based or non-values based) and time was used as the within-subject factor. For professors, a within-subjects design was used, ignoring class as the between-subject factor since there was only one professor per class. It was expected that in the student data the main effect of time would be significant, but that it would not be significant for the professors' data.

It was also expected that classes would be heterogeneous. To quantify this, the intraclass correlation coefficient was calculated to understand how much of the observed variance was due to class differences. It was expected that there would be differences between classes; however, to allow a direct test of the significance of the difference in change across time in professors as opposed to students, a follow up analysis was conducted ignoring the factor of class. That is, in a between $\mathrm{x}$ within design where the between-subject factor was participant type (professor or student) and the within-subject factor was time, the interaction between participant type and time was explicitly tested.

\subsection{Measures}

Professors and students were asked to complete a questionnaire packet on beliefs, values, attitudes, and their impressions of the classroom setting. The questionnaire was 15 pages long and took approximately 25 minutes to complete. Professors and students were given almost identical questionnaires. The only differences between the two questionnaires were the first and last page. The first page (after the coversheet) asked about attributes of being a professor (e.g., teaching topic, years of teaching) or of being a student (e.g., academic major, year in school). Professors self-assessed their own teaching ability using the TEB-Scale (described below); students assessed their professor's teaching ability using the same scale. The measures used have been validated in the research domain and are described in detail.

\subsubsection{Demographics}

The first page of the professors' questionnaire asked for responses on gender, age, years teaching, the topic(s) they are teaching, religious and political preference. The cover page of the students' questionnaire asked for responses on gender, age, type of student [undergraduate or graduate], year in school, academic major, religious and political preference.

\subsubsection{Rokeach Value Survey (RVS)}

As mentioned earlier, the Rokeach Value Survey (RVS) is a well-known instrument for measuring values. The RVS measures 18 terminal values and 18 instrumental values. Terminal values refer to desirable end-states of existence, such as inner harmony, a world of peace, and an exciting life whereas instrumental values are preferred modes of behavior, such as love, cleanliness, forgiveness, and logic. When respondents are given the RVS to complete, they are instructed to first rank the 18 terminal values and then the 18 instrumental values from 1 to 18 into an order "of importance to YOU, as guiding principles in YOUR life" (Rokeach, 1973, p. 27, original italics). The RVS has been 
tested for validity as well as used by social scientists across disciplines and cultures.

\subsubsection{Goal, Social, and Mode Values Inventories (GSVI, MVI)}

Braithwaite and Law (1985) developed three value inventories based on the RVS and tested them for reliability in a sample of 208 university students. The Goal Values Inventory measures values for personal goals (e.g., a sense of accomplishment) and is combined with the Social Values Inventory which asks students to judge the importance of societal goals in guiding their personal actions and judgments about national and international events. Together they are called the GSVI. The subscales in the GSVI are based on the terminal values found in the Rokeach Value Survey and focus on measuring values with desirable end-states. The subscales for the GSVI are: International Harmony and Equality, National Strength and Order, Traditional Religiosity, Personal Growth and Inner Harmony, Physical Well-being, Secure and Satisfying Interpersonal Relationships, Social Standing, Social Stimulation, and Individual Rights. The Mode Values Inventory (MVI) contains items that look at how respondents may or may not emulate behavioral patterns. The authors again based the subscales on Rokeach Value Survey, this time on the instrumental values, so that the MVI examines preferable modes of behavior. The subscales for the MVI are: Positive Orientation to Others, Competence and Effectiveness, Propriety in Dress and Manners, Religious Commitment, Assertiveness, Withdrawal from Others, Carefreeness, Honesty, Thriftiness, and Getting Ahead. Thus, the GSVI may be viewed as an assessment of terminal values and the MVI as an assessment of instrumental values. The GSVI has a median test-retest reliability coefficient of .62. The MVI has a median test-retest reliability coefficient of .61. The GSVI and MVI have been used in the university setting to better understand the role that moral emotions play in the psychological health of university students by asking participating students to focus on the level of congruence or incongruence between their personal moral commitments and their behaviors (Hall, Gow, and Penn, 2011).

\subsubsection{Values-in-Action (VIA)}

Park and Peterson (2006) also developed the Values-in-Action (VIA) inventory (see page 32). The Values in Action classification, a validated and reliable self-report questionnaire, offers a way to understand the kinds of qualities that may encompass and enhance a life of meaning, purpose, and value. As described earlier, the VIA identifies six overarching virtues: wisdom, courage, humanity, justice, temperance, and transcendence virtues. The following presents the definition for each virtue: (1) Wisdom and knowledge - the acquisition and use of knowledge; (2) Courage - the exercise of will to accomplish goals in the face of external/internal opposition; (3) Humanity - the tending and befriending of others; (4) Justice - the civic strengths that underlie healthy community life; (5) Temperance - the protection against excess; (6) Transcendence - the connections to the larger universe that provide meaning.

\section{Results}

\subsection{Participants}

At the start of the semester during the first week of classes, 688 participants completed the questionnaire. The sample consisted of 14 professors and 674 students. At the end of the semester during the last week of classes, 550 participants completed the questionnaire. The sample consisted of 14 professors and 536 students. Each student who completed the questionnaire both the first week of the semester ("Time 1") and the last week of the semester ("Time 2") had their data matched in the final dataset. From the approximately 700 unique participants who completed the questionnaire, 14 professors and 414 student participants had data collected from both the start and end of the semester. Independent groups $t$ tests were conducted to examine if there were significant differences in GSVI, MVI, and subscale means between participants who completed the questionnaire in both Time 1 and Time 2 and participants who did not complete the study at Time 2 . There were no detected significant differences for most of the subscales. However, for the GSVI, the two groups were found to significantly differ for Social Standing $[t(671)=$ $-2.306, p=.021$, Cohen's $d=-.182]$, and for Social Stimulation [t(669) $=-2.626, p=.009$, Cohen's $d=-.210]$. For both subscales, those who did not complete the study had higher means $\left(M_{\text {Standing }}=3.275, M_{\text {Stimulation }}=3.979\right)$ than those who completed the study $\left(M_{\text {Standing }}=3.123, M_{\text {Stimulation }}=3.814\right)$. For the MVI subscales, similar results were found for Carefreeness. Those who did not complete the study had a significantly higher mean than those who did complete the study, $M=3.252, M=3.109$, respectively, $t(665)=-2.324, p=.020$, Cohen's $d=-.183$.

\subsubsection{Difference between Professors and Students}

Because of the widely varying sample sizes of the two groups, it was expected that there would be considerably less power to detect change in the professors than to detect change in the students; thus, estimates of effect size are reported with the expectation that the student's effect size would be larger than that of the professors. This was both 
supported and opposed by the findings. Students' absolute value of the effect sizes for directional change (Cohen's $d$ ) ranged from .003 to .109 with a mean of .043 and professors' ranged from .00 to .549 , with a mean of .199. Unexpectedly, professors consistently had higher effect sizes than students. Part of the explanation for this may be that students were nested into heterogeneous classes, some of which increased and some of which decreased on a particular scale, with the changes tending to balance out over classes. Using a sign test, it was found that professors reported higher effect sizes more frequently than students, and this was significantly greater than chance [relative frequency of higher effect sizes for professors $=90 \%$, relative frequency of higher effect sizes for students $=10 \%, p$ $<.001]$.

The demographics for both professors and students were analyzed. Gender, age, and religious status were of specific interest due to their impact on values and beliefs: priority and perspective across specific values may differ due to one's gender, age, and/or religiosity (Goldscheider \& Goldscheider, 1988; Robinson-Wood, 2016).

In the sample of professors $(n=14), 9(64 \%)$ were male; the average age was 51 years with the youngest professor being 31 years and the oldest being 66 years. Ethnic variety was limited: 12 of the 14 professors were Caucasian (86\%), one was Hispanic, and one was European. There was higher diversity in religious status: two professors (14\%) reported no religious beliefs, five (36\%) reported being Atheist or Agnostic, five (36\%) were Protestant, one (7\%) was Catholic, and one (7\%) was Jewish.

In the sample of students $(n=414), 39 \%$ were male; the average age was 23 years, with ages ranging from 18 to 66 years. Eighty eight percent of the sample reported they were undergraduate level students. The majority of the sample reported their ethnicity as Caucasian (48\%) or Hispanic (32\%) with smaller percentages being Asian (5\%), Native American (3\%), African American (2\%), Middle Eastern (1\%), or "Mixed/Other" (6\%). Students also reported their religious status: $23 \%$ were Protestant, 22\% were "none", $17 \%$ were Atheist or Agnostic, 20\% were Catholic, 7\% were Spiritual, $2 \%$ were Buddhist or Hindu, and 1\% was Muslim.

\subsubsection{Participant Categories}

Various categories were established to analyze the data. Data were first categorized by department. Seven academic departments were represented in the sample: the Honors College (17\%), Psychology (39\%), Education (7\%), Computer Science (5\%), Math \& Statistics (16\%), Earth \& Planetary (12\%, EPS), and Environmental Science (4\%, ENVS). Another category was "class type." Participants were classified as being either in a class that was "values-based," meaning that the purpose of the course was to discuss value-based topics (e.g., human rights, spiritual beliefs), or a class that was non-values based, meaning that the purpose of the course was to learn a defined set of information (e.g., formulas, facts, methods). The Honors College, Psychology, and Education courses were categorized as "values-based" and the Computer Science, Math \& Statistics, EPS, and ENVS were categorized as "non-values based." From the sample of 414 participants, $63 \%$ of students were in values-based classes, $37 \%$ were in non-values based. Finally, since data were collected from multiple classes taught by the same professor, data were categorized by course code. There were 20 different courses represented in this dataset.

3.2 Hypothesis 1: Overall, students will demonstrate value change over time while professors' values will remain relatively stable over time

It was hypothesized that professors' values would remain stable over time while students' values changed from the start to the end of the semester. Both professors' and students' values were found to change over time, but students showed greater change for their values as measured by the MVI. The mean difference between professors and students was similar for the GSVI. Professors' mean difference for the GSVI overall was .233 and students' was .210. For the MVI overall, professors' mean difference was .186 but students' was .247 . The averages of the mean differences for the GSVI and MVI subscales were also calculated. The average of the mean differences for the GSVI subscales was .365 for professors and .388 for students. The average of the mean differences for the MVI subscales was .375 for professors, and .455 for students. However, as summarized in Table 1, students more frequently had higher mean differences, meaning their values are changing to a greater extent on more subscales than professors. Out of the 21 values examined, students were found to be changing more than professors for 16 of them. A sign test was used and found that the frequency of students changing more than professors was significantly greater than chance [relative frequency of greater change for students $=76 \%$, relative frequency of greater change for professors $=24 \%, p=.027]$. 
Table 1. Comparison of GSVI and MVI Mean Absolute Differences for Professors and Students

\begin{tabular}{|c|c|c|c|c|}
\hline Values & $\begin{array}{l}\text { Student Mean } \\
\text { Absolute } \\
\text { Difference }\end{array}$ & $\begin{array}{c}\text { Professor Mean } \\
\text { Absolute } \\
\text { Difference }\end{array}$ & $\begin{array}{c}\text { Students } \\
\text { changing more }\end{array}$ & $\begin{array}{c}\text { Professors } \\
\text { changing more }\end{array}$ \\
\hline GSVI Overall & .210 & .233 & & $\mathrm{X}$ \\
\hline International Harmony \& Equality & .340 & .250 & $\mathrm{x}$ & \\
\hline National Strength \& Order & .495 & .321 & $\mathrm{x}$ & \\
\hline Traditional Religiosity & .414 & .411 & $\mathrm{x}$ & \\
\hline Personal Growth \& Inner Harmony & .278 & .357 & & $X$ \\
\hline Physical Well-being & .395 & .167 & $\mathrm{x}$ & \\
\hline Secure \& Satisfying Interpersonal Relationships & .362 & .314 & $\mathrm{x}$ & \\
\hline Social Standing & .505 & .500 & $\mathrm{x}$ & \\
\hline Social Stimulation & .484 & .464 & $\mathrm{x}$ & \\
\hline Individual Rights & .394 & .631 & & $X$ \\
\hline MVI Overall & .247 & .186 & $\mathrm{x}$ & \\
\hline Positive Orientation to Others & .299 & .255 & $\mathrm{x}$ & \\
\hline Competence \& Effectiveness & .299 & .258 & $\mathrm{x}$ & \\
\hline Proprietary in Dress \& Manners & .366 & .276 & $\mathrm{x}$ & \\
\hline Religious Commitment & .532 & .482 & $\mathrm{x}$ & \\
\hline Assertiveness & .488 & .429 & $\mathrm{x}$ & \\
\hline Withdrawal from Others & .565 & .571 & & $X$ \\
\hline Carefreeness & .492 & .262 & $\mathrm{x}$ & \\
\hline Honesty & .574 & .714 & & $\mathrm{X}$ \\
\hline Thriftiness & .421 & .321 & $\mathrm{x}$ & \\
\hline Getting Ahead & .510 & .286 & $\mathrm{x}$ & \\
\hline
\end{tabular}

To examine value change in students from the start to the end of the semester, the SPSS MANOVA routine was used. MANOVA was used to look at change over time while still accounting for the heterogeneity between classes. The use of MANOVA allowed for the unique variance across classes to be pooled and used as a single error term. Since classes were also of varying sizes, the smallest having four student participants and the largest having 91, the use of Type III sums of squares helped prevent effects in larger classes from overshadowing potential effects present in smaller classes. It was also expected that courses which focused on value-based topics would increase in their values over time but non-values based classes were expected to show no change over time or even possible decreases.

MANOVA was used to test the interaction between time and courses for the GSVI overall, MVI overall, and the subscales. Because now the concern is not just with magnitude of change but with direction of change, signed difference scores (subtracting scores at Time 1 from those at Time 2) were used as the dependent variable instead of absolute value of differences. Results from these analyses are shown in Table 2. The interaction between time and courses for the GSVI overall and its subscales were not significant indicating that change over time for this measure was not a function of courses.

For the MVI and its subscales, courses were found to impact value change over time. Students' MVI overall score was found to significantly differ across the 19 classes, $F(17,384)=2.44, p=.001$ (see Figure 2). Follow up analyses found that values-based classes courses differed in the amount of change over time, $F(10,384)=3.53, p<.001$, while no significant difference in amount of change was detected with non-values based classes (see Figure 3). It was found that Honors courses showed significant differences across courses in amount of change, $F(6,384)=4.84$, $p<.001$. Two courses taught by the same instructor, UHON121CC and UHON301, specifically showed significantly different change in MVI overall. Calculating change by subtracting the Time 1 mean from the Time 2 mean so that positive differences indicated a greater endorsement of that value later in the semester, and negative differences indicated a decrease, the freshman class UHON121CC taught by this instructor showed a greater decrease in MVI overall $\left(\bar{D}_{M}=-.528\right)$ than the higher level course UHON301 $\left(\bar{D}_{M}=-.100\right), F(1,384)=8.11, p=.005$. Similarly, these two courses had a greater decline in MVI overall than observed in a senior level Honors seminar, UHON 401, $\left(\bar{D}_{M}=\right.$ $+.145), F(1,384)=8.11, p=.005$. Finally, two subgroups of Honors faculty were formed based on whether the professor was above or below the mean on Traditional Religiosity. The modest increase in MVI overall $\left(\bar{D}_{M}=+.040\right)$ for the four seminars (UHON201, UHON310-HDD, UHON121.17, UHON121.18) taught by the Honors faculty who were above the mean in Traditional Religiosity was significantly different than the overall mean decrease in MVI 
overall $\left(\bar{D}_{M}=-.161\right)$ seen in the three seminars (UHON401, UHON301, UHON121-CC) taught by faculty who were below the mean in Traditional Religiosity, $F(1,384)=5.34, p=.021$. Table 3 summarizes the change over time for MVI overall for each course.

Table 2. The Interaction of Course with Students' GSVI and MVI Value Change from Time 1 to Time 2 (dependent variable includes direction of change).

\begin{tabular}{lcc}
\multicolumn{2}{c}{ GSVI } & \\
\hline Measure & $F(17,373)$ & $p$ value \\
\hline GSVI Overall & .85 & .635 \\
International Harmony \& Equality & .96 & .505 \\
National Strength \& Order & 1.34 & .166 \\
Traditional Religiosity & 1.47 & .101 \\
Personal Growth \& Inner Harmony & .63 & .868 \\
Physical Well-being & .61 & .885 \\
Secure \& Satisfying Interpersonal Relationships & .56 & .920 \\
Social Stimulation & .65 & .850 \\
Social Standing & .79 & .702 \\
Individual Rights & 1.07 & .383 \\
\hline
\end{tabular}

critical $p$ values range $=[.05, .005] *$ significant by FDR criterion

MVI

\begin{tabular}{lcc}
\hline Measure & $F(17,384)$ & $p$ value \\
\hline MVI Overall & 2.44 & $.001^{*}$ \\
Positive Orientation to Others & 1.83 & .023 \\
Competence \& Effectiveness & 1.42 & .122 \\
Proprietary in Dress \& Manners & .93 & .543 \\
Religious Commitment & .91 & .568 \\
Assertiveness & 2.44 & $.001^{*}$ \\
Withdrawal from Others & .88 & .596 \\
Carefreeness & .73 & .770 \\
Honesty & .83 & .661 \\
Thriftiness & .91 & .567 \\
Getting ahead & 1.22 & .242 \\
\hline
\end{tabular}

critical $p$ values range $=[.05, .0045] *$ significant by FDR criterion

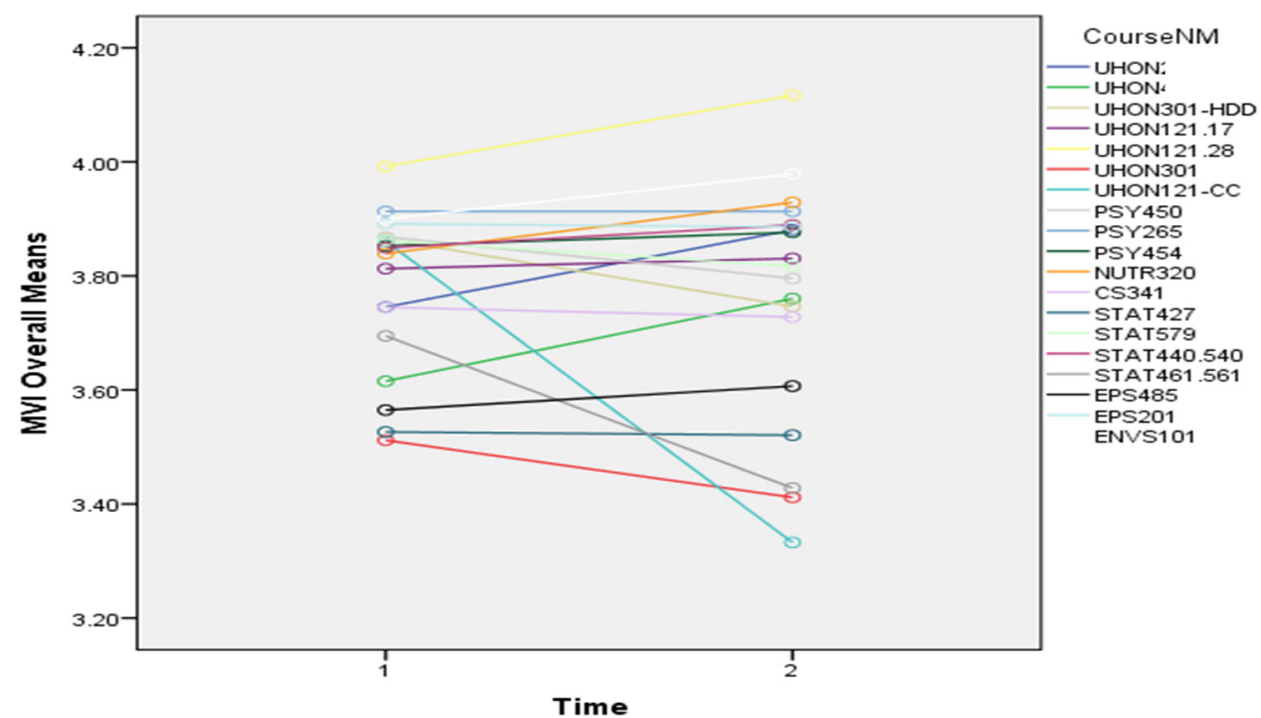

Figure 2. Students' MVI overall Found to Significantly Differ across Classes over Time 
Table 3. Change in MVI Overall from Time 1 to Time 2 for Individual Courses

\begin{tabular}{|c|c|c|c|c|c|c|}
\hline \multirow[b]{2}{*}{ Course } & \multirow[b]{2}{*}{ Mean Difference* } & \multirow[b]{2}{*}{ Time } & \multirow[b]{2}{*}{ Mean } & \multirow[b]{2}{*}{ Std. Error } & \multicolumn{2}{|c|}{$95 \%$ Confidence Interval } \\
\hline & & & & & Lower & Upper \\
\hline \multirow{2}{*}{ UHON201 } & \multirow{2}{*}{.136} & 1 & 3.745 & .104 & 3.541 & 3.950 \\
\hline & & 2 & 3.881 & .118 & 3.648 & 4.113 \\
\hline \multirow{2}{*}{ UHON401 } & \multirow{2}{*}{.145} & 1 & 3.615 & .109 & 3.400 & 3.831 \\
\hline & & 2 & 3.760 & .125 & 3.515 & 4.005 \\
\hline \multirow{2}{*}{ UHON301-HDD } & \multirow{2}{*}{-.118} & 1 & 3.864 & .082 & 3.703 & 4.026 \\
\hline & & 2 & 3.746 & .093 & 3.563 & 3.930 \\
\hline \multirow{2}{*}{ UHON121.17 } & \multirow{2}{*}{.018} & 1 & 3.813 & .116 & 3.584 & 4.041 \\
\hline & & 2 & 3.831 & .132 & 3.571 & 4.090 \\
\hline \multirow{2}{*}{ UHON121.28 } & \multirow{2}{*}{.125} & 1 & 3.992 & .147 & 3.703 & 4.281 \\
\hline & & 2 & 4.117 & .167 & 3.788 & 4.445 \\
\hline \multirow{2}{*}{ UHON301 } & \multirow{2}{*}{-.100} & 1 & 3.512 & .104 & 3.308 & 3.716 \\
\hline & & 2 & 3.412 & .118 & 3.179 & 3.644 \\
\hline \multirow{2}{*}{ UHON121-CC } & \multirow{2}{*}{-.528} & 1 & 3.861 & .099 & 3.666 & 4.055 \\
\hline & & 2 & 3.333 & .113 & 3.111 & 3.554 \\
\hline \multirow{2}{*}{ PSY450 } & \multirow{2}{*}{-.072} & 1 & 3.868 & .091 & 3.689 & 4.047 \\
\hline & & 2 & 3.796 & .104 & 3.592 & 3.999 \\
\hline \multirow{2}{*}{ PSY265 } & \multirow{2}{*}{.00} & 1 & 3.913 & .042 & 3.830 & 3.997 \\
\hline & & 2 & 3.913 & .048 & 3.818 & 4.008 \\
\hline \multirow{2}{*}{ PSY454 } & \multirow{2}{*}{.024} & 1 & 3.852 & .034 & 3.785 & 3.920 \\
\hline & & 2 & 3.876 & .039 & 3.799 & 3.953 \\
\hline & & 1 & 3.839 & .063 & 3.715 & 3.963 \\
\hline NUTR320 & .090 & 2 & 3.929 & .072 & 3.788 & 4.070 \\
\hline & & 1 & 3.745 & .075 & 3.597 & 3.893 \\
\hline CS341 & $-.01 /$ & 2 & 3.728 & .086 & 3.559 & 3.896 \\
\hline STAT427 & 005 & 1 & 3.526 & .055 & 3.417 & 3.635 \\
\hline S1A142I & -.005 & 2 & 3.521 & .063 & 3.397 & 3.645 \\
\hline & & 1 & 3.862 & .147 & 3.573 & 4.151 \\
\hline SТАТร79 & -.045 & 2 & 3.817 & .167 & 3.489 & 4.146 \\
\hline & 040 & 1 & 3.849 & .099 & 3.655 & 4.044 \\
\hline S1A 1440.540 & .040 & 2 & 3.889 & .113 & 3.668 & 4.111 \\
\hline STAT461 561 & 267 & 1 & 3.695 & .116 & 3.466 & 3.923 \\
\hline S1A1461.561 & $-.26 /$ & 2 & 3.428 & .132 & 3.168 & 3.688 \\
\hline FPS485 & 042 & 1 & 3.565 & .095 & 3.378 & 3.751 \\
\hline EPS485 & .042 & 2 & 3.607 & .108 & 3.395 & 3.819 \\
\hline & & 1 & 3.891 & .056 & 3.781 & 4.002 \\
\hline EPS201 & -.005 & 2 & 3.886 & .064 & 3.760 & 4.012 \\
\hline FNVS 101 & 079 & 1 & 3.900 & .075 & 3.752 & 4.048 \\
\hline ENVSIOI & .019 & 2 & 3.979 & .086 & 3.810 & 4.147 \\
\hline
\end{tabular}

*Mean difference $\left(\bar{D}_{M}\right)=$ Time 2 minus Time 1 


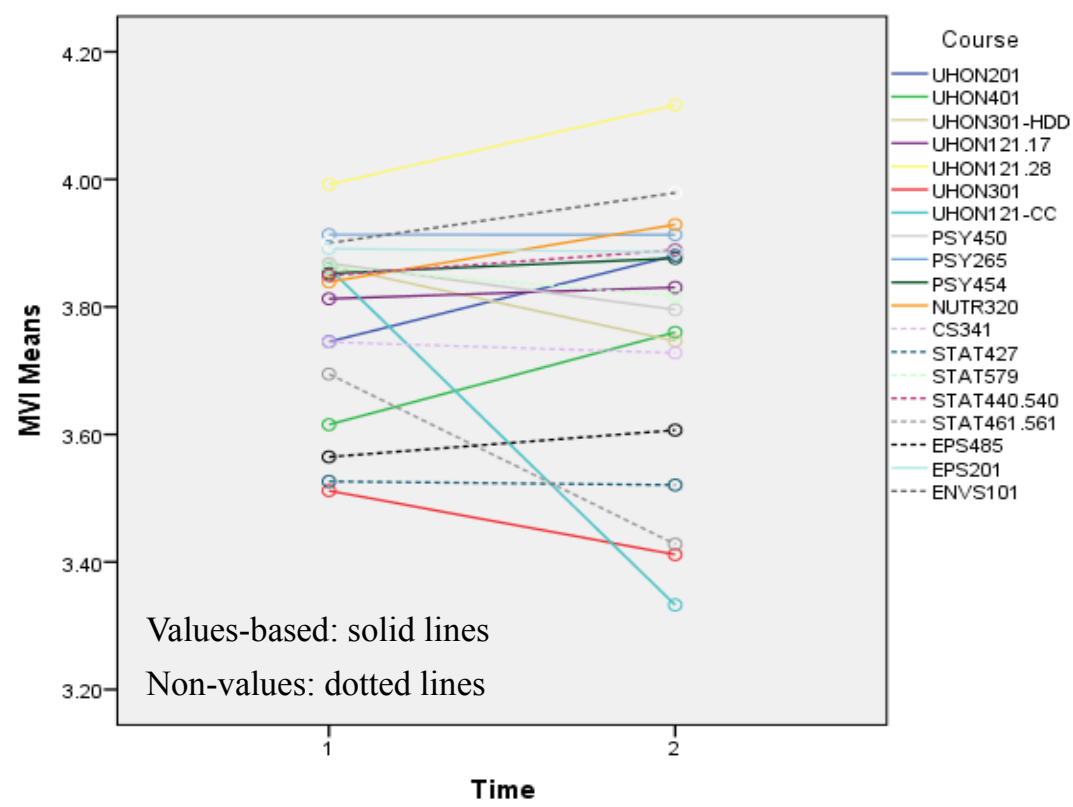

Figure 3. Students' MVI overall for Values-Based Classes Courses Found to Significantly Differ in the Amount of Change over Time, but not for Non-Values Based Classes

Table 4. Comparison of VIA Mean Absolute Differences for Professors and Students

\begin{tabular}{|c|c|c|c|c|}
\hline Values & $\begin{array}{c}\text { Student Mean } \\
\text { Absolute Difference }\end{array}$ & $\begin{array}{c}\text { Professor Mean } \\
\text { Absolute Difference }\end{array}$ & $\begin{array}{c}\text { Students } \\
\text { changing more }\end{array}$ & $\begin{array}{c}\text { Professors } \\
\text { changing more }\end{array}$ \\
\hline Appreciation of Beauty & .451 & .333 & $\mathrm{x}$ & \\
\hline Bravery & .444 & .485 & & $\mathrm{x}$ \\
\hline Love & .390 & .212 & $\mathrm{x}$ & \\
\hline Prudence & .541 & .424 & $\mathrm{x}$ & \\
\hline Teamwork & .490 & .455 & $\mathrm{x}$ & \\
\hline Creativity & .463 & .333 & $\mathrm{x}$ & \\
\hline Curiosity & .457 & .333 & $\mathrm{x}$ & \\
\hline Fairness & .436 & .212 & $\mathrm{x}$ & \\
\hline Forgiveness & .484 & .242 & $\mathrm{x}$ & \\
\hline Gratitude & .407 & .515 & & $\mathrm{x}$ \\
\hline Honesty & .378 & .333 & $\mathrm{x}$ & \\
\hline Hope & .417 & .242 & $\mathrm{x}$ & \\
\hline Humor & .424 & .227 & $\mathrm{x}$ & \\
\hline Perseverance & .448 & .485 & & $\mathrm{x}$ \\
\hline Judgment & .484 & .424 & $\mathrm{x}$ & \\
\hline Kindness & .383 & .242 & $\mathrm{x}$ & \\
\hline Leadership & .420 & .394 & $\mathrm{x}$ & \\
\hline Love of Learning & .463 & .394 & $\mathrm{x}$ & \\
\hline Humility & .507 & .515 & & $\mathrm{x}$ \\
\hline Perspective & .390 & .394 & & $\mathrm{x}$ \\
\hline Self-Regulation & .463 & .576 & & $\mathrm{x}$ \\
\hline Social Intelligence & .442 & .303 & $\mathrm{x}$ & \\
\hline Spirituality & .407 & .212 & $\mathrm{x}$ & \\
\hline Zest & .474 & .182 & $\mathrm{x}$ & \\
\hline
\end{tabular}




\subsubsection{Values in Action (VIA) Analyses}

\subsubsection{Professors}

$t$ tests were again used to test for value change over time. Unexpectedly, professors' values significantly changed for 22 of the 24 subscales. According to the FDR criterion, Kindness and Love were not found to change over time. This again shows that professors' values are not as stable as predicted over time.

\subsubsection{Students}

$t$ tests were also used to test for students' value change over time. Value change was highly significant for all values $(p<.001)$. This supports the hypothesis that students' values tend to fluctuate over time.

These findings again only partially supported the hypothesis that professors' values would remain stable while students' values changed from Time 1 to Time 2 . These findings show that both professors' and students' values are changing. However, as summarized by Table 4, students more frequently had higher mean differences, meaning their values are changing at a greater rate on more subscales than professors, Students: $\bar{D}_{M}=.427$, Professors: $\bar{D}_{M}=.348$. Out of the 24 values examined, students were found to be changing more than professors for 18 of them. A sign test was used and found again that students significantly changed more often than professors and this was greater than chance [relative frequency of greater change for students $=75 \%$, relative frequency of greater change for professors $=25 \%, p=.023]$.

MANOVA was also used to test the interaction between time and courses for the VIA subscales. Results from these analyses are shown in Table 5. The interaction between time and courses for all the VIA subscales were not significant indicating that change over time for this measure was not a function of courses.

Table 5. The Interaction of Course with Time, That Is, Tests Are of the Whether Difference in Students' VIA Values from Time 1 to Time 2 Varied across Courses (dependent variable includes direction of change).

\begin{tabular}{lcc}
\multicolumn{3}{c}{ VIA } \\
\hline Value & $F(16,198)$ & $p$ value \\
\hline Appreciation of Beauty & .76 & .730 \\
Bravery & 1.72 & .045 \\
Creativity & .60 & .880 \\
Curiosity & .50 & .947 \\
Fairness & .64 & .845 \\
Forgiveness & .78 & .712 \\
Gratitude & .73 & .763 \\
Honesty & .80 & .683 \\
Hope & .89 & .578 \\
Humor & 1.37 & .162 \\
Humility & .87 & .607 \\
Judgment & .92 & .547 \\
Leadership & 1.55 & .086 \\
Love & 1.02 & .434 \\
Love of Learning & .96 & .504 \\
Kindness & .67 & .824 \\
Perseverance & .61 & .874 \\
Perspective & .81 & .669 \\
Prudence & 1.89 & .023 \\
Self-Regulation & 1.98 & .016 \\
Social Intelligence & .87 & .609 \\
Spirituality & .68 & .810 \\
Teamwork & .54 & .922 \\
Zest & .60 & .880 \\
\hline
\end{tabular}

critical $p$ values range $=[.05, .0021] *$ significant by FDR criterion 


\subsection{Hypothesis 2: Students'Attributes Will Influence Level of Value Change}

Students were examined to see how different attributes influenced value change. It was expected that students who were younger (21 or under), had less college experience (freshman and sophomores), reported a weak adherence to values at the start of the semester, reported not being religious, or had little to no religious commitment would report higher levels of value change compared to their counterparts. It was also anticipated that gender would be influential and so this was added as a predictor to the model for exploratory purposes.

Two stepwise regression analyses were run to understand the strength of these six predictors: age, college year, initial commitment to values, reported religious status, levels of religious commitment, and gender. The dependent variables, GSVI absolute change and MVI absolute change, were calculated by taking the absolute difference between the average score for Time 1 and Time 2 for each of the GSVI and MVI's respective subscales and summing them to arrive at a final score of absolute change for the GSVI and for the MVI. Positive values indicated that the relationship was positive, meaning that as the predictor value increased so did value change (e.g., older students were associated with higher levels of value change) whereas negative values indicated that as the predictor variable increased, value change decreased (e.g., younger students were associated with lower levels of value change).

The first regression analysis looked at how these six variables predicted GSVI change. As shown in Table 6, initial commitment to values was found to have a significant, negative, moderately strong relationship with GSVI change, $r$ $=-.215, p<.001$. Similarly, levels of religious commitment were found to have a significant, negative but moderately weak relationship with GSVI change, $r=.120, p=.014$. There was also a strong, significant correlation between initial commitment and religious commitment $(r=.447, p<.001)$, suggesting moderate multicollinearity. Therefore, the final model only used initial commitment to values. Initial commitment was found to significantly predict change in GSVI over time, $t(335)=-4.022, p<.001, R^{2}=.046$. The final regression model found that for every unit increase in initial commitment, GSVI changed by -.637 units. Findings for all predictor variables are reported in Table 6.

Table 6. Analyses Reporting How Student Attributes Predict GSVI and MVI Absolute Change.

\begin{tabular}{|c|c|c|}
\hline \multicolumn{3}{|c|}{ GSVI } \\
\hline & $\begin{array}{c}\text { Pearson Correlation }(r) \\
\text { with GSVI change }\end{array}$ & $\begin{array}{l}p \text { value } \\
\text { (1-tailed) }\end{array}$ \\
\hline GSVI Absolute Change+ & 1.000 & \\
\hline Age $(0=$ under $21 \mathrm{yrs}, 1=21+\mathrm{yrs})$ & -.037 & .247 \\
\hline Year in Undergraduate $\left(0=1^{\text {st }}\right.$ or $2^{\text {nd }}$ year, $1=3^{\text {rd }}$ year +$)$ & -.022 & .341 \\
\hline Initial Commitment to Values $(0=$ low, $1=$ high $)$ & -.215 & $<.001 *$ \\
\hline Religious Status $(0=$ non-religious, $1=$ religious $)$ & -.078 & .077 \\
\hline Religious Commitment $(0=$ low, $1=$ high $)$ & -.120 & $.014 *$ \\
\hline Gender $(1=$ male, $2=$ female $)$ & .057 & .149 \\
\hline \multicolumn{3}{|c|}{$n=337$; critical $p$ values range $=[.05, .008] *$ significant by FDR criterion } \\
\hline \multicolumn{3}{|c|}{ +calculated by summing the absolute difference between the average score for Time 1 and Time 2 for each subscale } \\
\hline \multicolumn{3}{|c|}{ Unstandardized Coefficients } \\
\hline Final Model & Std. Error & $p$ value \\
\hline (Constant) & 32.419 & $<.001$ \\
\hline Initial Commitment to Values & -4.022 & $<.001 *$ \\
\hline \multicolumn{3}{|c|}{ MVI } \\
\hline & $\begin{array}{l}\text { Pearson Correlation }(r) \\
\text { with MVI Change }\end{array}$ & $\begin{array}{l}p \text { value } \\
\text { (1-tailed) }\end{array}$ \\
\hline MVI Absolute Change+ & 1.000 & \\
\hline Age $(0=$ under $21 \mathrm{yrs}, 1=21+\mathrm{yrs})$ & -.036 & .254 \\
\hline Year in Undergraduate $\left(0=1^{\text {st }}\right.$ or $2^{\text {nd }}$ year, $1=3^{\text {rd }}$ year +$)$ & -.075 & .086 \\
\hline Initial Commitment to Values $(0=$ low, $1=$ high $)$ & -.242 & $<.001^{*}$ \\
\hline Religious Status $(0=$ non-religious, $1=$ religious $)$ & -.230 & $<.001^{*}$ \\
\hline Religious Commitment $(0=$ low, $1=$ high $)$ & -.232 & $<.001^{*}$ \\
\hline Gender $(1=$ male, $2=$ female $)$ & -.088 & .055 \\
\hline
\end{tabular}

$n=337$; critical $p$ values range $=[.05, .008] *$ significant by FDR criterion 
+calculated by summing the absolute difference between the average score for Time 1 and Time 2 for each subscale

\begin{tabular}{rcccc}
\hline & \multicolumn{2}{c}{ Unstandardized Coefficients } & & \\
Final Model & $B$ & Std. Error & $t$ & $p$ value \\
\hline (Constant) & 5.434 & .187 & 29.060 & $<.001$ \\
Initial Commitment to Values & -.743 & .215 & -3.458 & $.001^{*}$ \\
Religious Status & & & & \\
(Non-religious vs. Religious) & -.675 & .215 & -3.133 & $.002^{*}$ \\
\hline
\end{tabular}

The second analysis, which tested the relationship between the six predictors and MVI change, found that three out of the six variables to significantly relate to MVI change. Initial commitment to values, religious status, and religious commitment all had significant, negative, moderately strong relationships with MVI change: Initial commitment: $r=$ $-.242, p<.001$; Religious status: $r=-.230, p<.001$; Religious commitment; $r=.232, p<.001$. There was also strong, significant correlation between religious status and religious commitment $(r=.648, p<.001)$ as well as between initial commitment and religious commitment $(r=.460, p<.001)$, suggesting moderate multicollinearity. The final model used initial commitment to values and religious status as predictors for MVI change. Initial commitment was found to significantly predict change in GSVI over time, $t(328)=-3.458, p=.001$. Similarly, religious status was also found to predict change in GSVI over time, $t(328)=-3.133, p=.002$. The final regression model found that for every unit increase in initial commitment, MVI change decreased by -.743 units, and for every unit increase in religious status, MVI change decreased by -.675 units. Overall, the model with both predictors accounted for a relatively small amount of the variance, $R^{2}=.086$.

All predictors had a negative correlation supporting the hypothesis that higher levels of change were related to lower levels of values commitment. Interestingly, the student attributes related to stage in life such as age and year in college as well as gender were not indicative of value change. Instead, the variables related to students' commitment to values and religious beliefs were strongly related to value change.

A test for the heterogeneity of regression found that the interaction was significant between class type and initial commitment to values, $F(1,331)=20.175, p=.002$, as well as between class type and religious status, $F(1,331)=$ $10.656, p=.040$. This indicated that there were significant differences in the predictive strength of these two variables between values based and non-values based classes. Unexpectedly, initial commitment to values and religious status were stronger predictors for non-values based classes rather than for values-based classes. Hence, follow up analyses were conducted to see if the six predictors affected GSVI and MVI change differently for values and non-values based classes. Regression analyses using the six predictors were first conducted using the data from values-based classes for the GSVI and MVI scores. The same analyses were then conducted for the non-values based classes' data.

For the values-based classes, only initial commitment to value had a significant, negative, moderately strong, relationship with GSVI change, $r=-.173, p=.004$. For every unit increase in initial commitment, GSVI change significantly decreased by $-.523, t(228)=-2.653, p=.009, R^{2}=.030$. Initial commitment to values, religious status, and religious commitment were all found to have significant, negative, moderately strong relationships with MVI change: Initial commitment to values: $r=-.209, p=.001$; Religious status: $r=-.214, p=.001$; Religious commitment: $r=-.250, p<.001$. The final model only included religious commitment. This was primarily because initial commitment and religious commitment were strongly related $(r=.396, p<.001)$, and religious commitment had a strong relationship with MVI change. Religious commitment significantly predicted MVI change, $t(228)=$ -3.901, $p<.001, R^{2}=.063$. As hypothesized, lower levels of religious commitment predicted higher levels of MVI change. For every unit increase in religious commitment, MVI change decreased by -.988 units. Results are summarized in Table 7. 
Table 7. Analyses Reporting How Student Attributes Predict GSVI and MVI Absolute Change in Values Based Classes

GSVI

\begin{tabular}{lcc}
\hline & $\begin{array}{c}\text { Pearson Correlation }(r) \\
\text { with GSVI change }\end{array}$ & $\begin{array}{c}p \text { value } \\
(1 \text {-tailed })\end{array}$ \\
\hline GSVI Absolute Change+ & 1.000 & .094 \\
Age $(0=$ under 21 yrs, $1=21+$ yrs $)$ & -.087 & .090 \\
Year in Undergraduate $\left(0=1^{\text {st }}\right.$ or $2^{\text {nd }}$ year, $1=3^{\text {rd }}$ year +$)$ & -.089 & $.004^{*}$ \\
Initial Commitment to Values $(0=$ low, $1=$ high $)$ & -.173 & .072 \\
Religious Status $(0=$ non-religious, $1=$ religious $)$ & -.097 & .065 \\
Religious Commitment $(0=$ low, $1=$ high $)$ & -.100 & .071 \\
Gender $(1=$ male, $2=$ female $)$ & & .071 \\
\hline
\end{tabular}

$n=230$; critical $p$ values range $=[.05, .008] *$ significant by FDR criterion

+ calculated by summing the absolute difference between the average score for Time 1 and Time 2 for each subscale

\begin{tabular}{rcccc}
\hline & \multicolumn{4}{c}{ Unstandardized Coefficients } \\
Final Model & $B$ & Std. Error & $t$ & $p$ value \\
\hline (Constant) & 4.032 & .160 & 25.241 & $<.001$ \\
Initial Commitment to Values & -.523 & .197 & -2.653 & $.009^{*}$ \\
\hline
\end{tabular}

\begin{tabular}{lcc} 
& MVI \\
\hline & $\begin{array}{c}\text { Pearson Correlation }(r) \\
\text { with MVI Change }\end{array}$ & $\begin{array}{c}p \text { value } \\
(1-\text { tailed })\end{array}$ \\
\hline MVI Absolute Change+ & 1.000 &. \\
Age $(0=$ under 21 yrs, $1=21+$ yrs $)$ & -.041 & .266 \\
Year in Undergraduate $\left(0=1^{\text {st }}\right.$ or $2^{\text {nd }}$ year, $1=3^{\text {rd }}$ year +$)$ & -.112 & .045 \\
Initial Commitment to Values $(0=$ low, $1=$ high $)$ & -.209 & $.001^{*}$ \\
Religious Status $(0=$ non-religious, $1=$ religious $)$ & -.214 & $.001^{*}$ \\
Religious Commitment $(0=10 w, 1=$ high $)$ & -.250 & $<.001^{*}$ \\
Gender $(1=$ male, $2=$ female $)$ & -.101 & .064 \\
\hline
\end{tabular}

$n=230$; critical $p$ values range $=[.05, .008] *$ significant by FDR criterion

+calculated by summing the absolute difference between the average score for Time 1 and Time 2 for each subscale

\begin{tabular}{rcccc}
\hline & \multicolumn{2}{c}{ Unstandardized Coefficients } & & \\
Final Model & $B$ & Std. Error & $t$ & $p$ value \\
\hline (Constant) & 5.185 & .198 & 26.228 & $<.001$ \\
Religious Commitment & -.988 & .253 & -3.901 & $<.001^{*}$ \\
\hline
\end{tabular}

For non-values classes, findings were similar to the overall regression analyses. Initial commitment to values and religious commitment again were the only predictors to significantly predict GSVI change: Initial commitment: $r=$ -.320, $p<.001$; Religious commitment: $r=-.196, p=.022$. The relationship between initial commitment and GSVI change was strong $(r=-.320)$, whereas the relationship between religious commitment and GSVI change was fairly weak, $r=-.196$, so only initial commitment was included in the final model. Initial commitment was found to significantly predict GSVI change, $t(105)=-3.463, p=.001, R^{2}=.103$. GSVI decreased by -.935 for every unit increase in initial commitment. For MVI change, initial commitment to values, religious status, and religious commitment again had strong, negative, significant relationships with MVI change: Initial commitment: $r=-.336, p$ $<.001$; Religious status: $r=-.280, p=.002$; Religious commitment: $r=-.215, p=.016$. MVI scores significantly decreased by -.995 for every unit increase in initial commitment $(t(98)=-2.825, p=.006)$, and significantly decreased by -.706 for every unit increase in religious status $(t(98)=-2.001, p=.048)$. The final model with these two predictors accounted for a moderately large part of the variance, $R^{2}=.148$. Results are displayed in Table 8 . 
Table 8. Analyses Reporting How Student Attributes Predict GSVI and MVI Absolute Change in Non-Values Based Classes

\begin{tabular}{lcc} 
& GSVI & \\
\hline & $\begin{array}{c}\text { Pearson Correlation }(r) \\
\text { with GSVI change }\end{array}$ & $\begin{array}{c}p \text { value } \\
(1 \text {-tailed })\end{array}$ \\
\hline GSVI Absolute Change + & 1.000 & .223 \\
Age $(0=$ under 21 yrs, $1=21+$ yrs $)$ & .074 & .199 \\
Year in Undergraduate $\left(0=1^{\text {st }}\right.$ or $2^{\text {nd }}$ year, $1=3^{\text {rd }}$ year +$)$ & .083 & $<.001^{*}$ \\
Initial Commitment to Values $(0=$ low, $1=$ high $)$ & -.320 & .264 \\
Religious Status $(0=$ non-religious, $1=$ religious $)$ & -.062 & $.022^{*}$ \\
Religious Commitment $(0=$ low, $1=$ high $)$ & -.196 & .482 \\
Gender $(1=$ male, $2=$ female $)$ & -.005 & \\
\hline
\end{tabular}

$n=337$; critical $p$ values range $=[.05, .008] *$ significant by FDR criterion

+ calculated by summing the absolute difference between the average score for Time 1 and Time 2 for each subscale

\begin{tabular}{rcccc}
\hline \multicolumn{5}{c}{ Unstandardized Coefficients } \\
Final Model & $B$ & Std. Error & $t$ & $p$ value \\
\hline (Constant) & 4.045 & .197 & 2.521 & $<.001$ \\
Initial Commitment to Values & -.935 & .270 & -3.463 & $.001^{*}$ \\
\hline
\end{tabular}

\begin{tabular}{lcc} 
& MVI & \\
\hline & $\begin{array}{c}\text { Pearson Correlation }(r) \\
\text { with MVI Change }\end{array}$ & $\begin{array}{c}p \text { value } \\
(1 \text {-tailed })\end{array}$ \\
\hline MVI Absolute Change+ & 1.000 & .412 \\
Age $(0=$ under 21 yrs, $1=21+$ yrs $)$ & -.023 & .453 \\
Year in Undergraduate $\left(0=1^{\text {st }}\right.$ or $2^{\text {nd }}$ year, $1=3^{\text {rd }}$ year +$)$ & -.012 & $<.001^{*}$ \\
Initial Commitment to Values $(0=$ low, $1=$ high $)$ & -.336 & $.002^{*}$ \\
Religious Status $(0=$ non-religious, $1=$ religious $)$ & -.280 & $.016^{*}$ \\
Religious Commitment $(0=$ low, $1=$ high $)$ & -.215 & .177 \\
Gender $(1=$ male, $2=$ female $)$ & -.093 & \\
\hline
\end{tabular}

$n=337$; critical $p$ values range $=[.05, .008] *$ significant by FDR criterion

+ calculated by summing the absolute difference between the average score for Time 1 and Time 2 for each subscale

\begin{tabular}{rcccc}
\hline \multicolumn{5}{c}{ Unstandardized Coefficients } \\
Final Model & $B$ & Std. Error & $t$ & $p$ value \\
\hline (Constant) & 5.393 & .277 & 19.487 & $<.001$ \\
Initial Commitment to Values & -.995 & .352 & -2.825 & $.006^{*}$ \\
Religious Status & & & & \\
(Non-religious vs. Religious) & -.706 & .353 & -2.001 & $.048^{*}$ \\
\hline
\end{tabular}

Overall, student attributes predicted value change but only initial commitment to values was a robust predictor for GSVI change. Initial commitment and religious commitment were robust predictors for MVI change. As hypothesized, students in both values and non-values classes who had lower levels of initial commitment of values and less religious commitment were more susceptible to value change.

\subsection{Hypothesis 3: Students Assimilate to Their Professor's Values}

To examine value assimilation, the RVS ranking scores for instrumental and terminal values at Time 1 and 2 for professors and each of their students were used. Each student's RVS ranked value position was noted separately for the 18 terminal and 18 instrumental values, for Time 1 and Time 2 . These value ranks were then correlated with the professor's ranking. Thus, four correlations were computed for each student with their professor's values: correlations of their instrumental values with their professor's at the beginning of the semester, correlations of their 
instrumental values with their professor's at the end of the semester, correlations of their terminal values with their professor's at the beginning of the semester, and correlations of their terminal values with their professor's at the end of the semester. It was predicted that change over time would be different between courses and class type (values vs. non-values), that is, the interaction would be significant in a between $\mathrm{x}$ within ANOVA of the correlations. It was also expected that mean correlations would increase significantly over time, that is, the main effect of the within-subject factor of time would be significant. Correlations were transformed using Fisher's $r$ to $z$ transformation before analysis. Box's $M$ found that for all tests the observed covariance matrices of the dependent variables were equal across groups $(p>.05)$.

To again account for students nested in classes, a mixed model analysis was used to determine if differences between classes influenced the relationship between professors' and students' terminal and instrumental values. The intraclass correlation coefficients (ICCs) were calculated to determine if nesting should be accounted for in the analysis. For the relationship between professors' and students' terminal values, $13.00 \%$ of the observed variance was due to differences between classes. For the relationship between professors' and students' instrumental values, $6.16 \%$ of the observed variance was due to differences between classes. The ICCs indicated heterogeneity between classes so nested model analyses were used. Course code was used as random nested factors to account for differences between classes.

\subsubsection{Courses}

MANOVA was used to test the interaction between time and courses for the relationships between professors' and students' terminal and instrumental values. The difference was calculated between the professor-student relationship by subtracting Time 1 from Time 2 for both terminal values and instrumental values. The difference was used as the dependent variable.

For the relationship between professors' and students' terminal values, courses were found to significantly impact value assimilation over time, that is, the course $\mathrm{x}$ time interaction was significant, $F(17,329)=3.61, p<.001$. The difference in mean change in correlations between values-based courses and non-values based course did not approach significance, $F(1,17)=0.01, p=.916$, nor did the test of overall change from Time 1 to Time 2 approach significance, $F(1,17)=0.62, p=.443$. Follow up analyses for the significant interaction of course $\mathrm{x}$ time revealed that there were significant differences in the amount of change over time for both values-based courses, $F(10,329)=$ $4.23, p<.001$, and non-values based courses, $F(7,329)=2.73, p=.009$.

Contrast analyses for values-based classes found that there was a significant difference between psychology and Honors courses. More specifically, psychology courses showed a greater increase than the Honors college [Psychology: $\bar{D}_{M}=.108$, Honors: $\left.\bar{D}_{M}=-.013, F(1,329)=18.99, p<.001\right]$. As in Hypothesis 1 , mean differences were calculated by subtracting the Time 1 mean from the Time 2 mean so that positive differences indicated an endorsement of that value, and negative differences indicated a decrease. Also, psychology courses showed significant differences in amount of change, $F(2,329)=7.31, p=.001$. There was not a significant difference between PSY265 and PSY450 $(p>.05)$, which were taught by the same professor, but there was a significant difference between PSY265 + PSY450 with PSY454, $F(1,329)=10.84, p=.001$. PSY265 and PSY450 both showed large increases over time whereas PSY454 showed a slight increase: PSY265+PSY450: $\bar{D}_{M}=.184$, PSY454: $\bar{D}_{M}=.053$.

Contrast analyses for non-values based classes found a significant difference among the Statistics \& Math courses, $F(3,329)=4.99, p=.002$. STAT440 + STAT461, which were taught by the same professor, were significantly different than STAT427 + STAT579, which were also both taught by the same professor, $F(1,329)=9.72, p=.002$. The relationship between the professor and students' terminal values greatly decreased for STAT440+STAT461 over time but moderately increased for STAT427+STAT579: STAT440+STAT451: $\bar{D}_{M}=-.121$, STAT427+STAT579: $\bar{D}_{M}$ $=.089$ (see Table 9a). 
Table 9. Change in the Relationship between Professors' and Students' Values overall from Time 1 to Time 2 for Departments

a) Terminal Values

\begin{tabular}{lcccccc}
\hline & $\begin{array}{c}\text { Mean Difference* } \\
\text { Department }\end{array}$ & & & \multicolumn{3}{c}{$95 \%$ Confidence Interval } \\
\hline \multirow{2}{*}{ Honors } & -.013 & 1 & .200 & .026 & .150 & .251 \\
& & 2 & .187 & .026 & .135 & .238 \\
Psychology & .108 & 1 & .072 & .017 & .039 & .104 \\
& & 2 & .180 & .017 & .146 & .213 \\
Education & -.052 & 1 & .299 & .040 & .220 & .379 \\
& & 2 & .247 & .041 & .166 & .329 \\
Computer Science & -.029 & 1 & .298 & .051 & .197 & .399 \\
& & 2 & .269 & .052 & .166 & .372 \\
Math \& Statistics & .031 & 1 & .132 & .028 & .077 & .187 \\
& & 2 & .163 & .029 & .107 & .220 \\
Earth \& Planetary Science & .084 & 1 & .124 & .031 & .063 & .184 \\
& & 2 & .208 & .032 & .145 & .270 \\
Environmental Science & .075 & 1 & .026 & .048 & -.069 & .120 \\
& & 2 & .101 & .049 & .004 & .198 \\
\hline
\end{tabular}

*Mean difference $=$ Time 2 minus Time 1

b) Instrumental Values

\begin{tabular}{|c|c|c|c|c|c|c|}
\hline \multicolumn{5}{|c|}{ Mean Difference* } & \multicolumn{2}{|c|}{ 95\% Confidence Interval } \\
\hline Department & $\left(\bar{D}_{\mathrm{M}}\right)$ & Time & Mean & Std. Error & Lower & Upper \\
\hline \multirow{2}{*}{ Honors } & \multirow{2}{*}{-.015} & 1 & .212 & .024 & .165 & .259 \\
\hline & & 2 & .197 & .022 & .152 & 241 \\
\hline \multirow{2}{*}{ Psychology } & \multirow{2}{*}{-.032} & 1 & .184 & .015 & .154 & 215 \\
\hline & & 2 & .152 & .015 & .123 & 181 \\
\hline \multirow{2}{*}{ Education } & \multirow{2}{*}{-.201} & 1 & .159 & .037 & .085 & 232 \\
\hline & & 2 & -.042 & .035 & -.112 & .027 \\
\hline \multirow{2}{*}{ Computer Science } & \multirow{2}{*}{.039} & 1 & .210 & .047 & .117 & .303 \\
\hline & & 2 & 249 & .045 & .162 & .337 \\
\hline \multirow{2}{*}{ Math \& Statistics } & \multirow{2}{*}{.082} & 1 & .108 & .026 & .057 & 159 \\
\hline & & 2 & .190 & .024 & .142 & 238 \\
\hline \multirow{2}{*}{ Earth \& Planetary Science } & \multirow{2}{*}{-.01} & 1 & .151 & .028 & .096 & 207 \\
\hline & & 2 & 141 & .027 & .088 & 193 \\
\hline \multirow{2}{*}{ Environmental Science } & \multirow{2}{*}{.161} & 1 & .024 & .044 & -.063 & 111 \\
\hline & & 2 & .185 & .042 & .102 & 267 \\
\hline
\end{tabular}

*Mean difference $=$ Time 2 minus Time 1

Courses were also found to significantly impact value assimilation over time for the relationship between professors' and students' instrumental values, $F(17,328)=2.13, p=.006$ (see Figure 4). In addition, the main effect of type of class on amount of change in correlations was significant, $F(1,17)=4.55, p=.048$. As suggested by Figure 4, although non-values classes tended to start with lower student-professor correlations, the overall increase in student-professor correlations in the non-values based classes, $\bar{D}_{M}=, 054$, was greater than that in the values based classes, where the mean correlations actually declined, $\bar{D}_{M}=-.031$. Follow up analyses of the significant course $\mathrm{x}$ time interactions found that there were significant differences in the amount of change over time for values-based courses, $F(10,328)=2.23, p=.016$, but the non-values based only approached significance, $F(7,328)=1.99, p$ 
$=.056$.

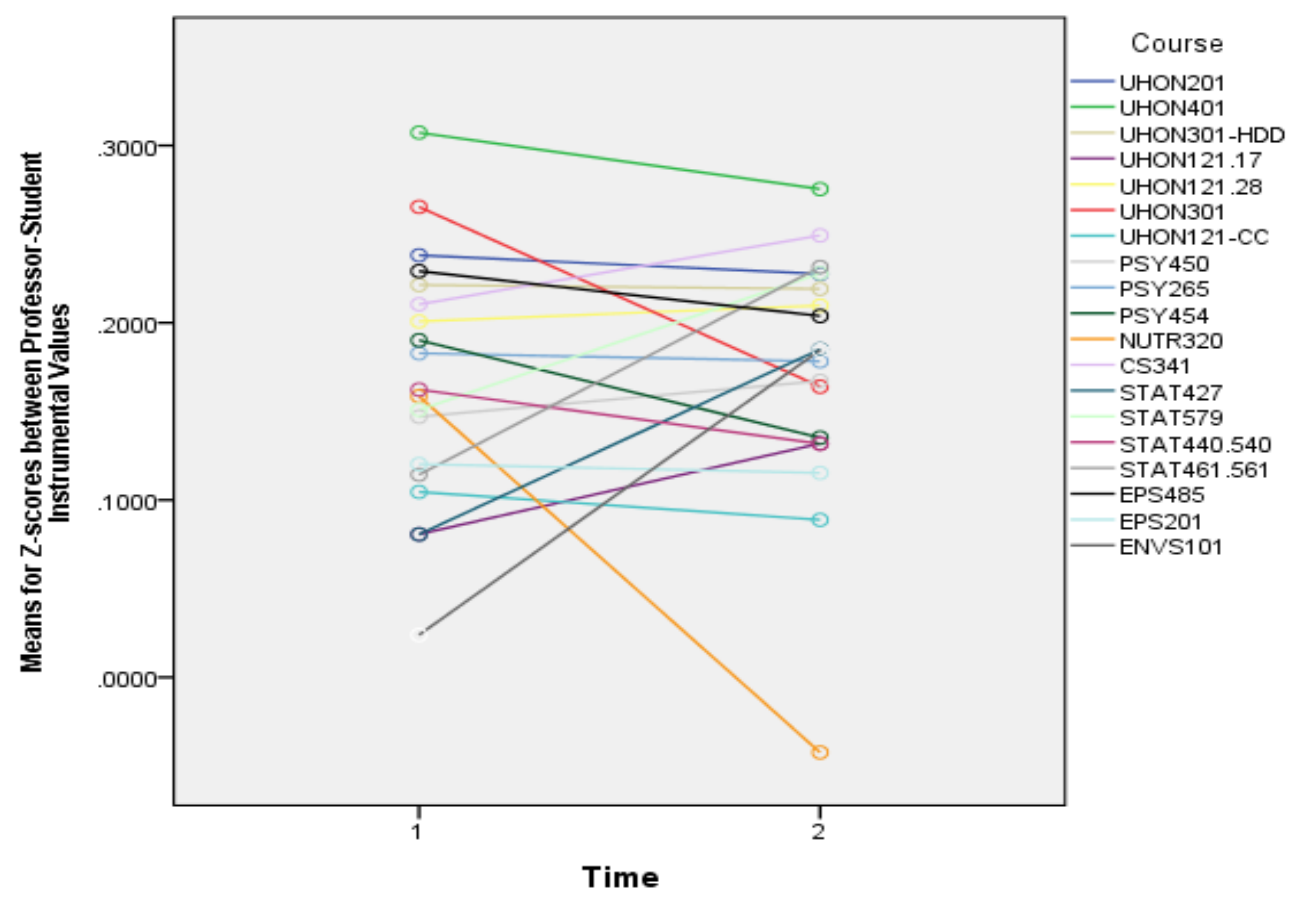

Figure 4. The Relationship between Professors' and Students' Instrumental Values Significantly Differed across Classes over Time

Contrast analyses for values-based classes found that there was a significant difference between education courses and psychology + Honors courses. Surprisingly, all the departments showed a decrease over time, but education showed greater decrease than the psychology + Honors college, [Education: $\bar{D}_{M}=-.201$, Psychology+Honors: $\bar{D}_{M}=$ $-.014, F(1,328)=17.26, p<.001]$. Department differences over time are reported in table $9 \mathrm{~b}$.

These findings suggest that both departments and individual classes impact value assimilation as well as dissimilation.

\subsubsection{Profile Analysis}

To further test if value assimilation occurs, a multivariate analysis was used to examine the difference between professors' and students' VALUEs for values-based and non-values based courses. Profile analyses were conducted for the GSVI and the MVI subscales. Profile analyses look at three different dimensions: parallelism, levels, and flatness. Parallelism looks at whether subgroups (professors vs. students; values vs. non-values based courses) differ by varying amounts for specific values dimensions. The levels test examines if the overall endorsement of values is different between subgroups (professors vs. students; values vs. non-values based courses). Flatness indicates if there are varying degrees of value endorsement across subscales, averaging for both professors and students. It was expected that professors' and students' values would become more similar over time and that values-based classes would show more value convergence over time than the non-values classes. Hence, the four-way interaction between Time, Participant type, Class type, and Values subscales was tested. It was also expected that professors' and students' in general would converge in their values over time. The relationship between Participant type, Time, and Value subscales was tested. Values-based classes were anticipated to have higher value over time than non-values based classes, so the Class type $\mathrm{x}$ Time $\mathrm{x}$ Values subscales interaction was also tested. Wilks's Lambda criterion was used based on guidance from Tabachnick and Fidell (2013). Profile analyses were conducted, first for the GSVI subscales and then for the MVI subscales.

The first analysis examined the profile for GSVI subscale scores between professors and students for values and non-based classes over time. The four-way interaction between class type (values vs. non-values) and participant type (professors vs. students) for GSVI subscales over time was not significant, $F(8,399)=1.045, p=.402$, indicating that GSVI values did not change over time as a function of both participant type and class type. Both the three-way interactions between Time, Class type, and GSVI subscale and the three-way interaction between Time, 
Participant type, and GSVI subscale were also, unexpectedly, not found to be significant, $p>.05$. This suggests that, contrary to predictions, change over time for GSVI subscales was not occurring as a function of class type $[F(8,401)$ $=.434, p=.901]$ or of participant type $[F(8,401)=.903, p=.514]$.

The primary hypothesis was that that professors' and students' GSVI values would change over time due to value convergence. The levels test found that professors' and students' values significantly differed, $F(1,408)=4.038, p$ $=.045$. Value convergence would be demonstrated through the nature of change over time, meaning that professors' and students' values would significantly differ at the start of the semester and then not be significantly different at the end of the semester. The contrary was found: at Time 1, the mean GSVI value averaging across subscales were not significantly different, $[F(1,423)=2.011, p=.157]$ between professors and students, but they were significantly different in levels at Time $2,[F(1,410)=6.646, p-.010]$. Similarly, as displayed in Figure 5, the test of the simple two-way interaction of Participant type by GSVI subscale was not significant at Time $1,[F(8,416)=1.059, p=.391]$ but at Time 2 it was significant, $[F(8,403)=2.211, p=.026]$. This suggests divergence between professors' and students' in GSVI values over time rather than convergence.

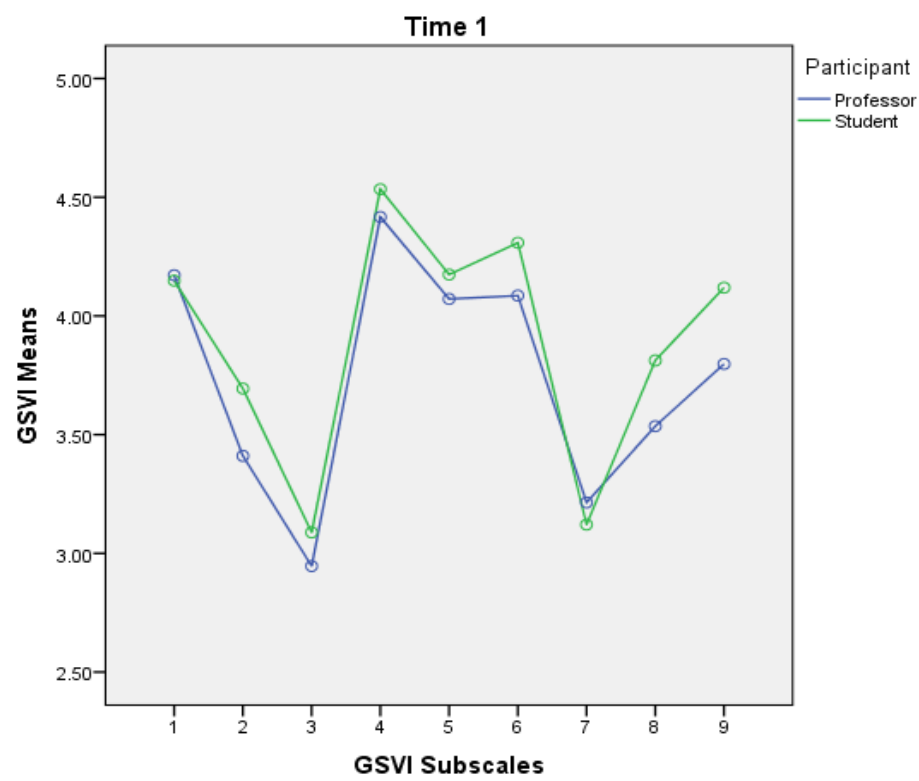

Time 2

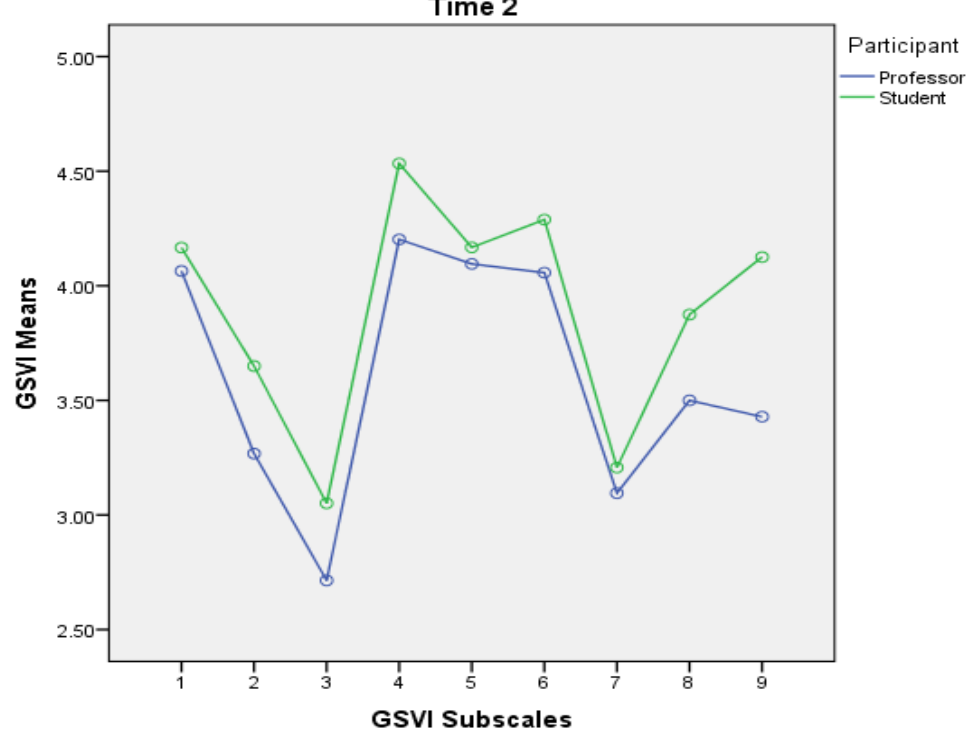

GSVI Subscales

1 - International Harmony \& Equality

2 - National Strength

3 - Traditional Religiosity

4 - Personal Growth

5 - Physical Well-being

6 - Secure \& Satisfying Relationships

7 - Social Standing

8 - Social Stimulation

9 - Individual Rights

Figure 5. Significant Difference in GSVI Subscale Means between Professors and Students at Time 2, But not Time 1. 
Next, the MVI subscale scores between professors and students for values and non-based classes over time were examined. The four-way interaction between class type (values vs. non-values) and participant type (professors vs. students) for MVI subscales over time was not significant, $F(9,393)=.839, p=.581$, indicating that MVI values did not change over time as a function of participant type and class type. The three-way interactions for both Time, Class type, and GSVI subscale and the three way interaction for Time, Participant type, and MVI subscale were again not found to be significant, $p>.05$. This suggests that, contrary to predictions, change over time for MVI subscales was not occurring as a function of class type $[F(9,395)=1.160, p=.320]$ or of participant type $[F(9,395)=.693, p$ $=.693]$.

It was again expected that professors' and students' MVI values would change over time due to value convergence. The levels test found that professors' and students' values did not significantly differ, $F(1,403)=2.691, p=.102$. Again contrary to expectations, the mean MVI value averaging across subscales was significantly different between professors and students at both Time $1[F(1,409)=5.496, p=.020]$ and at Time $2[F(1,410)=12.665, p<.001]$. Similarly, as shown in Figure 6, the test of the simple two-way interaction of Participant type by MVI subscale was not significant at Time $1,[F(9,411)=1.686, p=.090]$ but did significantly differ at Time $2[F(9,401)=2.360, p$ $=.013]$. This again suggests divergence between professors' and students' in MVI values over time rather than convergence.
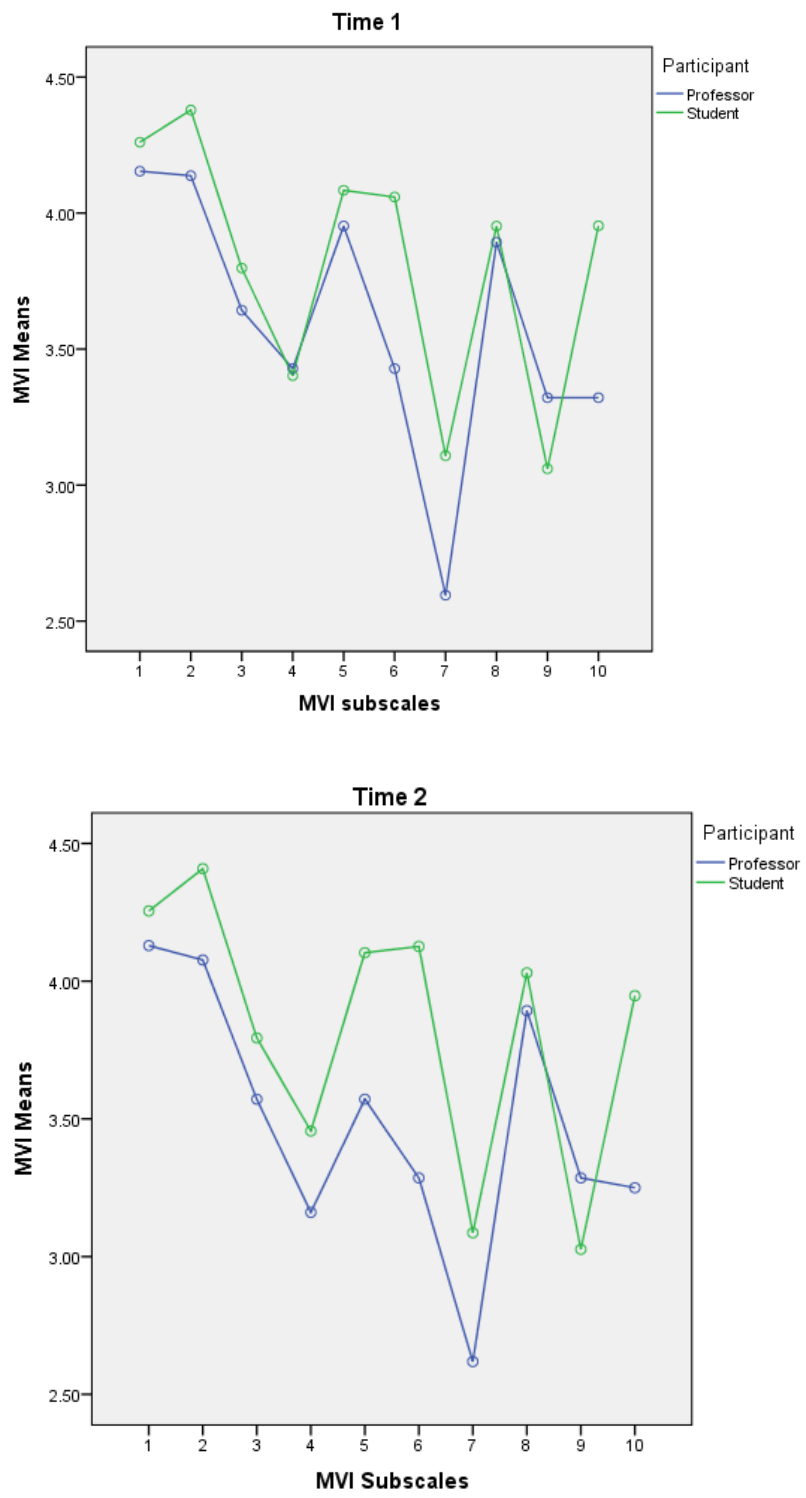

MVI Subscales

1 - Positive Orientation to Others

2 - Competence \& Effectiveness

3 - Propriety

4 - Religious Commitment

5 - Assertiveness

6 - Withdrawal from People

7 - Carefreeness

8 - Honesty

9 - Thriftiness

10 - Getting ahead

Figure 6. Significant Difference in MVI Subscale Means between Professors and Students at Time 2, but not Time 1. 


\subsubsection{Value Assimilation for Individual Values}

Correlation analyses were used to investigate value assimilation between professors and students for specific values, as measured by the GSVI and MVI subscales. A summary score for the professor and class was calculated for each course. The change in professor and students' values over time (Time 2 summary score minus Time 1 summary score) was also calculated for each subscale. Pearson correlation coefficients were calculated. If the relationship between students' values and professors' values at Time 1 was not significant but was significant at Time 2, this would indicate value assimilation. Similarly, if the change in students' values over time correlated with professors' overall values, a positive relationship would also indicate assimilation.

As shown in Table 10, the relationship between professors' and students' religious commitment at Time 1 was very weak $\left(r_{z}=.037\right)$. At Time 2 , there was a positive, strong, significant relationship $\left(r_{z}=.492, p=.033\right)$. The delta from Time 1 to Time 2 in value convergence was .455. The change in students' religious commitment values from Time 1 to Time 2 was also found to be significantly and positively correlated to professor's religious commitment at Time 2 $\left(r_{z}=.588, p=.008\right)$. Similarly, professors' level of traditional religiosity was found to be a significant predictor of students' change in religious commitment $\left(r_{z}=.519, p=.023\right)$ and students' overall religious commitment $\left(r_{z}=.477\right.$, $p=.039)$. Professors' overall religious commitment was also found to be a predictor for students' change in religious commitment $\left(r_{z}=.604, p=.006\right)$. These findings clearly demonstrate the influence of professors' religious beliefs and values on students' religious beliefs and values.

Table 10. Correlations between Professors' and Students' Religiosity Demonstrating Value Assimilation ( $p$ value in parentheses).

\begin{tabular}{|c|c|c|c|c|}
\hline \multirow{4}{*}{$\begin{array}{l} \\
\text { Student Religious Commitment at Time } 1 \\
\text { Student Religious Commitment at Time } 2 \\
\text { Difference between Student Religious } \\
\text { Commitment (T2-T1) }\end{array}$} & \multicolumn{2}{|c|}{$\begin{array}{c}\text { Professor Religious } \\
\text { Commitment at Time } 1\end{array}$} & \multicolumn{2}{|c|}{$\begin{array}{c}\text { Professor Religious } \\
\text { Commitment at Time } 2\end{array}$} \\
\hline & \multicolumn{2}{|c|}{$.037(.879)$} & \multicolumn{2}{|c|}{$.142(.562)$} \\
\hline & \multicolumn{2}{|c|}{$.407(.084)$} & \multicolumn{2}{|c|}{$.492^{*}(.033)$} \\
\hline & \multicolumn{2}{|c|}{$.585^{* *}(.008)$} & \multicolumn{2}{|c|}{$.588^{* *}(.008)$} \\
\hline \multicolumn{5}{|c|}{$n=19, *$ significant if $p<.05 \quad * *$ significant if $\mathrm{p}<.01$} \\
\hline & $\begin{array}{c}\text { Professor } \\
\text { Traditional } \\
\text { Religiosity } \\
\text { Grand Average }\end{array}$ & $\begin{array}{c}\text { Professor } \\
\text { Traditional } \\
\text { Religiosity } \\
\text { T2-T1 } \\
\end{array}$ & $\begin{array}{c}\text { Professor } \\
\text { Religious } \\
\text { Commitment } \\
\text { Grand Average }\end{array}$ & $\begin{array}{c}\text { Professor } \\
\text { Religious } \\
\text { Commitment } \\
\text { T2-T1 } \\
\end{array}$ \\
\hline $\begin{array}{l}\text { Student Traditional Religiosity Grand } \\
\text { Average }\end{array}$ & $.213(.380)$ & $.184(.450)$ & $-.029(.906)$ & $.257(.287)$ \\
\hline $\begin{array}{l}\text { Student Traditional Religiosity } \\
\text { T2-T1 }\end{array}$ & $.061(.804)$ & $.183(.454)$ & $-.061(.804)$ & $.121(.621)$ \\
\hline $\begin{array}{l}\text { Student Religious Commitment Grand } \\
\text { Average }\end{array}$ & $.477^{*}(.039)$ & $.396(.094)$ & $.323(.177)$ & $.331(.166)$ \\
\hline $\begin{array}{l}\text { Student Religious Commitment } \\
\text { T2-T1 }\end{array}$ & $.519^{*}(.023)$ & $.378(.111)$ & $.604^{* *}(.006)$ & $.275(.255)$ \\
\hline
\end{tabular}

\section{Discussion}

This study focused on how students' values are affected by the university setting, specifically the classroom environment. It might generally be expected that college students' academic journey will foster value anchoring and value change but the findings from this study shed light on what factors are contributing to that change. Overall, it was found that in the academic setting values do change over time, for students as well as for professors, that students demonstrate greater value change over time, and that students' attributes influence how much their values change. Some values such as Getting Ahead were found to consistently be highly valued at the start of the semester as well as at the end. Other values such as Traditional Religiosity and Religious Commitment were found to both change in different directions across the semester as well as be influenced by the classroom environment and professor. 
It was expected that values would not change for professors but would change for students. This hypothesis was partially supported. Students' showed significant change in their values over time, as expected. Contrary to predictions, professors were also found to significantly change in their values over time. Students were still found to have higher degrees of change more frequently than professors, indicating that students demonstrate greater levels of value change.

Having professors show significant value change over the semester was both unexpected as well as concerning. As discussed in the introduction, positions of authority and steadfast values influence dynamics such as value anchoring and assimilation. Those with less stable values tend to be guided by those with stronger values. The hope for the classroom setting is that it is a place where students can openly consider and anchor their own values in relation to their worldview by hearing the opinions of their professors and colleagues (Emmanuel-Aviña \& Delaney, 2014). It is more difficult for students to consider their own values in relation to their professors when their professors' values are not consistent over time. One unexpected finding was that the professors' level of Traditional Religiosity was predictive of change in MVI overall. Students with professors who reported lower levels of Traditional Religiosity decreased in MVI overall over the semester whereas students who had professors with higher levels showed an increase over time. Therefore, it was concluded that while department and class type could be important to shaping values at an institutional level, the course material, the professors' worldview or emphasis on specific values, or both were found to have stronger, more direct impact on students.

\subsection{Students' Attributes Influence Value Change}

This study found that various students' attributes contributed differently to value change, some being more influential than others. Age, year in school, and gender are demographics that describe attributes of a student and what life stage he or she is in. None of these attributes were found to be strong predictors of value change. On the other hand, student attributes reflecting where they were in conviction and commitment to values were found to predict value change. Initial commitment to values, reported religious status, and religious commitment were all robust predictors of change. Findings supported the hypotheses that the weaker a student was in one or more of these areas of value commitment, the more susceptible he or she was to value change. In all cases, higher levels of value change were found for those reporting lower levels of initial value commitment, non-religious status, and lower levels of religious commitment.

As with Hypothesis 1, the university setting, specifically the classroom context, exposes students to new worldviews, perspectives, and philosophies. These exposures provide an opportunity for students to consider their current value system and perhaps refine their values or change them completely based on new information. Conversely, students who have strong, grounded, and established values, regardless of where they are in their life journey, are less likely to change their values based on new information. In fact, students with strong convictions may see opposing worldviews as an opportunity to strengthen their own values as they contemplate the gaps and weaknesses in other worldviews and learn how to defend their personal position. Students may have other authority figures and resources, such as mentors, political networks, or religious leaders, outside of the academic setting which shape their personal convictions and keep their values steadfast even when faced with opposing or competing information in the classroom context.

\subsection{Students Assimilate to Professors' Values}

Overall, students were found to assimilate to their professors' values for terminal values. One interpretation of this is that some classes focus on topics having an inherent goal or aim, such as seeking solutions to threats to human rights (UHON401), investigating suffering, sexuality, and the meaning of life (UHON301), or caring for the blue planet (ENVS201). Through the course material, professors may have encouraged their students to value principles that facilitate achieving a greater goal. The relationship between professors' and students' instrumental values was not found to increase over the semester, but class type was found to have an interesting impact on instrumental values. The relationship between professors' and students' instrumental values was found to increase over time for non-values based classes but decrease for values-based classes. One interpretation is that students in non-values based classes tended to have lower values compared to values-based classes as well as less convergence with the professors' values at the start of the semester. This provided more room for students in non-values based classes for both their values to change over time and for value assimilation. For values-based classes, findings could again be attributable to students in value-based classes already having higher levels of values that were in alignment with their professors and, as a result, had less room to assimilate. Another interpretation could be that values-based classes had room for discussion and consideration of various worldviews. Students had the opportunity to consider and refine their values but did not feel obligated to converge with their professor's perspective. Another argument is that 
professors' changing values were more apparent through dialogue in the values-based classes, making it more difficult for students to unthinkingly assimilate to their values.

Religiosity continued to stand out as a value impacted by the college context. This was especially true for value assimilation. Overall change in students' religious commitment was predicted by both professor's traditional religiosity and religious commitment. The more professors valued religious experiences and beliefs such as salvation, spiritual experiences, fidelity, and devotion, the more the students are reported valuing these religious attributes. Conversely, if professors did not value these religious attributes, students also decreased their value of religiosity. Ultimately, professors' religious beliefs, values, and attitudes have a strong impact on their students' religious values. Less religious professors encourage their students to be less religious, and more religious professors encourage their students to value religiosity more.

Ultimately, these findings demonstrate that the classroom context, comprised of the course material and the professor's presence, is more indicative of value change and assimilation than class type or department. Students' values are impacted by their professors' beliefs and the course material that they are learning in both positive and negative ways. These findings also may indicate that there are contributing factors to value change outside of the classroom context and academic setting. Students are learning new information in the classroom but they are also having novel exposures in various settings such as their home life, social interactions, extracurricular activities, and work experiences which might impact their values.

As past research literature (e.g., Lutz, Boon, Xue, 2016; Astin \& Astin, 2015; Pascarella \& Feldman, 2005; Astin, 1993; Vreeland \& Bidwell, 1966) as well as the findings of this current study suggest, there is evidence that students acquire the values of their academic institution, course content, and professors. To better understand the nature of values in the academic setting as well as how and why university students may alter their personal values, it important to understand how value change and assimilation occurs over the academic journey. Methodology and metrics from other relevant, empirical literature, such as in clinical psychology (Schwehn \& Schau, 1990; Strupp, 1980), and the quantification of values through the Rokeach Value Survey, the Goal, Social, and Mode Values Inventories, and Value-in-Action inventory enable researchers to examine change in values over time and examine the relationship between professor and students' values. As found in this study, specific classroom environments, reflecting both the professor and the course material, influence students to change, refine, and/or anchor their beliefs, values, and attitudes. This study especially found value change and assimilation to occur for values surrounding religiosity and faith-based beliefs, even in a sample of students attending a secular, public university.

\subsection{Strengths and Weaknesses}

The current study was strong with a large sample size, a diverse range of courses, departments, and professors, and validated, reliable measures to quantify values. Professors were willing to permit researchers to come into their classroom two different times, which meant that values were measured directly in the academic context. The contrast between non-values and values-based classes also allowed researchers to target some of the potential sources of change. In regard to weaknesses, At the start of the semester, there were 674 students who completed the questionnaire, and at the end of the semester, there were 550 students; but only 414 students had data for both times, which was $62 \%$ of the data collected at Time 1 and $75 \%$ of the data collected at Time 2 . It could be argued that students who continue to faithfully attend class have higher levels of motivation and have other values that differ from students who skip class. These differences would not have been accounted for in the current study's findings. The classification of values and non-based values classes were based on department and not the goal of the professors. A professor may have very strong beliefs about politics, for example, and incorporate that into all the courses they teach, whether it be statistics, accounting, or other courses where values are not expected to be discussed. Finally, hypotheses in this study were generally supported but data was only collected from a single, public university. Value change and assimilation may vary across different types of colleges and universities.

Generalizability is also an issue. Hypotheses in this study were generally supported but data was only collected from a single, public university. Value change and assimilation may vary across different types of colleges and universities. The findings from the clinician-therapist context suggest that value assimilation may be the strongest when there is a face-to-face, one-on-one relationship; personal topics are discussed; there is an authority figure; and the relationship continues over a period of time. Academic institutions with smaller classes, more frequent professor-student interactions, and/or classes with discussion-based formats may demonstrate more value assimilation than those with larger and lecture-based classes. 


\subsection{The VAE Applies to Both Clinical and Educational Contexts}

The more one learns about the potential for professors and the classroom environments they nurture to foster students' value change and assimilation, the clearer the ethical concerns become, especially when the change is unsolicited and subconscious. However, there are different perspectives on how the influence on values should be handled. Regarding religious and spiritual values, What shall we tell the children? is a polemic written by psychologist Nicholas Humphrey on how religions abuse the minds of children (Humphrey, 2003). Famous atheist, Richard Dawkins, cites Humphrey's work as a call to "work to free the children of the world from the religions which, with parental approval, damage minds too young to understand what is happening to them" (Dawkins, 2006). Freeing adolescents from the influence of religious-based environments so that they can make their own biased-free decisions includes banishing faith-based institutions and insisting that adolescents and young adults attend value-free, secular colleges and universities. Nevertheless, as found in this current study, beliefs, values, and attitudes, especially those regarding religiosity and spirituality, are impacted by the people and content students are surrounded by, not by the label or categorization of their school. Students leave the faith they were reared in or acquire religious beliefs at both secular and faith-based institutions. This proposition is supported by research that has shown that rates for both apostasy and religious commitment do not differ much between faith-based and secular institutions (Smith \& Sikkink, 2003). Students are influenced not by the over-arching category of the school but by the individual academic, social, and philosophical experiences they have with their professors and in the classroom.

Therefore, if the call from the research, philosophy, and general community is to encourage individuals to formulate their values through independent, personal decisions, instead of moving students from one value-based institution (e.g., faith-based) to another value-based institution (secular and/or agnostic), perhaps a better method would be transparency and consent to allow individuals to best make their decisions. An environment of transparency and consent would prevent subconscious value assimilation and encourage an academic setting where values were respected, students directly were accountable for considering their personal beliefs, and values and attitudes were openly discussed and considered (see Smith, Vicuña, \& Emmanuel, 2015).

One domain that provides guidance for how to accomplish an open, honest environment is clinical psychology. As psychologist Tjeltveit (1986) stated, therapists engage in four types of ethically problematic behaviors when value conversion occurs: reducing client freedom, failing to inform clients of the possibility of value conversion, violating the therapeutic contract, and operating beyond the limits of their competence. Although eliminating one's personal values from therapy is impossible, Tjeltveit proposed five solutions to alleviate subconscious value conversion: therapist training, therapist-client matching, referrals, changing roles, and informed consent. As therapists and clinicians in training become more aware of their biases, they can better learn what role their values play in therapy. This will enable therapists to be honest in the therapeutic relationship and thus protect client autonomy and enhance the overall therapeutic relationship. Clinical psychology's emphasis on informed consent helps to guide the therapeutic relationship, specifically through the American Psychology Association Code of Ethics, Standard 10.01 "Informed Consent to Therapy." Standard 10.01 requires clinical psychologists to "inform clients/patients as early as is feasible in the therapeutic relationship about the nature and anticipated course of therapy..." Although informed consent is a debatable topic among psychologists, Tjeltveit (1986) proposes different degrees of informed consent to notify clients of potential value conversion to enhance the therapist-client relationship as well as provide balanced reassurance with a realistic portrayal of risks. Adequate levels of informed consent allow therapy clients to be aware of value assimilation risk without providing so much information that clients are alarmed and decline treatment. Clinical psychology literature suggests that a standard written consent form which highlights risks and potential outcomes should be provided to the client. Tjeltveit offers a continuum of disclosure levels which should be chosen based on the nature of therapy. The level of disclosure can be as simple as, "Clients are likely to change in therapy," or as extensive as the following:

"Clients are likely to change in therapy; this may include changes in...their values. While therapists strive to be objective regarding values and clients are always free to hold and adopt values of their choice, in some instances, clients' values change in the direction of therapist values. Therefore, it may be important for you to know some of my values. My moral values are [for instance] liberal, my religious conviction is agnostic, and my political values are liberal Democratic. Again, you are entirely free to hold whatever values you wish.” (p. 529)

The level of informed consent allows for clients to ask direct questions about therapist values, to be reassured that they have the right to agree or disagree, and understand that they are not in a value-free, neutral context.

The same concerns in the clinical environment exist in the academic environment. Students have a professor as their authority and may feel obligated to agree with their professor which reduces their freedom. Professors most often do 
not inform students of the possibility of value assimilation and may not even be aware of how their level of authority subconsciously draws students' values to their own. Students attend public universities for the opportunity to hear from their professors and colleagues about various worldviews and opinions and be free agents who decide what is wrong and right. The student-professor contract is at risk of being violated if students are told what to believe or are denied exposure to multiple perspectives (e.g., evolution, intelligent design, creationism). Professors also run the risk of operating beyond the limits of their competence if they tell students what to believe or they present material that is beyond the course topic.

Since both the clinical and academic settings are contexts where a power differential is present and the individuals of lesser power have values that are malleable and vulnerable, lessons can be learned from the clinical literature and applied to the education setting. It seems unrealistic to ask students to sign informed consent forms when they start taking a course from a professor. It is essential, however, for professors and professionals in academia to inform their students that the classroom context is not value-free, but rather a setting where students have an opportunity to consider their values. With this in mind, it is critical for professors to be aware of their own values and be as transparent as necessary about those values with their students while encouraging an environment of open dialogue. Value change and assimilation may still occur but, instead of having subconscious, or even unwanted change, students would be more aware, proactive, conscious, and in control of the change.

\subsection{Summary of Findings}

In conclusion, the design, analyses, and findings of this study leveraged empirical literature from various domains to quantitatively research how values change and assimilate to figures of authority. More specifically, the study considered how the presence of a power differential within various settings, such as academia, influence individuals to alter their beliefs, values, and attitudes to align with someone considered to be superior and how value assimilation can have both positive and negative consequences. University students constitute one such population that is susceptible to value change due to the authority and role of their professors.

The findings from this study indicate that value change does occur over a semester timeframe for both students and professors. Students attending university are in an environment that allows for them to consider their personal values and refine, alter, or change them completely based on information they learn in their classes. However, students may be unaware of how their beliefs, values, and attitudes are being affected by the course material they are learning and the worldviews their professor brings to the class. Students may subconsciously align their worldview to their professor and professors, through their level of authority, may subconsciously encourage it. To ensure that the academic setting does not provoke a decrease in values or subconscious, unethical value conversion, professors and academia professionals should be transparent and not force their values into course material and onto their students. In the same way, the classroom setting can be used by professors to nurture growth and maturity of thought, by being respectful and considerate of various worldviews and promoting discussion of students' values in class.

\section{References}

Astin, A. W., \& Astin, H. S. (2015). Achieving equity in higher education: The unfinished agenda. Journal of College and Character, 16(2), 65-74. http://dx.doi.org/10.1080/2194587X.2015.1024799

Astin, A. W. (1993). What matters in college? Four critical years revisited. San Francisco, CA: Jossey-Bass Publishers.

Astin, A.W. (1977). Four critical years. Effects of college on beliefs, attitudes, and knowledge. San Francisco, CA: Jossey-Bass Publishers, Inc.

Astin, A. W. (2012). Assessment for excellence: The philosophy and practice of assessment and evaluation in higher education. Lanham, MD: Rowman \& Littlefield Publishers.

Astin, A. W., Astin, H. S., \& Lindholm, J. A. (2011). Assessing students' spiritual and religious qualities. Journal of College Student Development, 52(1), 39-61. http://dx.doi.org/10.1353/csd.2011.0009

Beutler, L. E. (1981). Convergence in counseling and psychotherapy: A current look. Clinical Psychology Review, 1(1), 79-101. http://dx.doi.org/10.1016/0272-7358(81)90020-9

Bok, D. C. (1990). Universities and the future of America. Durham, NC: Duke University Press.

Braithwaite, V. A., \& Law, H. G. (1985). Structure of human values: Testing the adequacy of the Rokeach Value Survey. Journal of Personality and Social Psychology, 49(1), 250-263. http://dx.doi.org/10.1037/0022-3514.49.1.250 
Braskamp, L. A., Trautvetter, L. C., \& Ward, K. (2016). Putting students first: How colleges develop students purposefully. San Francisco, CA: John Wiley \& Sons.

Browning, M. H., Stern, M. J., Ardoin, N. M., Heimlich, J. E., Petty, R., \& Charles, C. (2017). Investigating the sets of values that community members hold toward local nature centers. Environmental Education Research, 23(9), 1291-1306. http://dx.doi.org/10.1080/13504622.2016.1177713

Cieciuch, J. (2017). Exploring the complicated relationship between values and behaviour. In S. Roccas \& L. Sagiv (Eds.), Values and Behavior (p. 237-247). Cham: Springer. https://doi.org/10.1007/978-3-319-56352-7_11

Cieciuch, J., \& Schwartz, S. H. (2017). Values and the human being. In M. van Zomeren \& J.F. Dovidio (Eds.), The Oxford Handbook of the Human Essence (p. 62). New York, NY: Oxford University Press. http://dx.doi.org/10.1093/oxfordhb/9780190247577.001.0001

Dawkins, R. (2006). Religion's real child abuse. The Richard Dawkins Foundation for Reason and Science. Retrieved from http://old.richarddawkins.net/articles/118-religion-39-s-real-child-abuse

Emmanuel-Aviña, G., \& Delaney, H. (2014). Professors' influence on students' beliefs, values, and attitudes in the classroom. Journal of College and Character, 15(4), 245-258.

Goldscheider, C., \& Goldscheider, F.K. (1988). Ethnicity, religiosity and leaving home: The structural and cultural bases of traditional family values. Social Forum, 3(4), 525-547. http://dx.doi.org/10.1007/BF01115413

Hall, A. N., Gow, K. G., \& Penn, M. L. (2011). Do chronic moral emotions mediate between value congruence and psychological wellbeing in university? In K. M. Gow and M. J. Celinski (Eds.), Wayfinding through life's challenges (p. 519-531). Hauppauge, NY: Nova Science Publishers.

Hindman, D. M. (2002). From splintered lives to whole persons: Facilitating spiritual development in college students. Religious Education, 97(2), 165-182. https://doi.org/10.1080/00344080290060923

Humphrey, N. (2002). The mind made flesh: Essays from the frontiers of psychology and evolution. New York, NY: Oxford University Press.

Hurt, H. T., Scott, M. D., \& McCroskey, J. C. (1978). Communication in the classroom. Reading, MA: Addison-Wesley.

Ingham, H.V., \& Love, O.R. (1954). The process of psychotherapy. New York, NY: McGraw-Hill.

Kessel, P., \& McBrearty, J.F. (1967). Values and psychotherapy: A review of the literature. Perceptual and Motor Skills, 25(1), 669-690. https://doi.org/10.2466/pms.1967.25.2.669

Kuron, L. K., Lyons, S. T., Schweitzer, L., \& Ng, E. S. (2015). Millennials' work values: Differences across the school to work transition. Personnel Review, 44(6), 991-1009. https://doi.org/10.1108/PR-01-2014-0024

Little, J. M., Gaier, S., \& Spoutz, D. (2018). The role of values, beliefs, and culture in student retention and success. In R. C. Black (Ed.), Critical Assessment and Strategies for Increased Student Retention (pp. 54-72). Hershey, PA: IGI Global. https://doi.org/10.4018/978-1-5225-2998-9.ch004

Lutz, D. J., Boon, A. T., \& Xue, X. (2016). Resolving ethical dilemmas in academic advising through core values and aspirational principles. Mentor: An Academic Advising Journal. Retrieved from https://dus.psu.edu/mentor/2016/06/resolving-ethical-dilemmas-in-academic-advising-through-core-values-andaspirational-principles/

Maxwell, S. E., \& Delaney, H. D. (2004). Designing experiments and analyzing data: A model comparison perspective (Vol. 1). New York, NY: Taylor \& Francis Group.

McCroskey, J. C., \& Richmond, V. P. (1983). Power in the classroom I: Teacher and student perceptions. Communication Education, 32(2), 175-184. https://doi.org/10.1080/03634528309378527

Meehl, P.E., \& McClosky, H. (1947). Ethical and political aspects of applied psychology. Journal of Abnormal and Social Psychology, 42(1), 91-98. https://doi.org/10.1037/h0058085

Miller, L. H. (2018). Global Order: Values and Power in International Relations. New York, NY: Routledge. p. xi.

Nelson, C. E. (1968). Anchoring to accepted values as a technique for immunizing beliefs against persuasion. Journal of Personality and Social Psychology, 9(4), 329-334. https://doi.org/10.1037/h0021255

Overbeck, J. R., \& Park, B. (2001). When power does not corrupt: Superior individuation processes among powerful perceivers. Journal of Personality and Social Psychology, 81(4), 549-565. 
https://doi.org/10.1037/0022-3514.81.4.549

Oyserman, D. (2015). Psychology of values. In J. D. Wright (Ed.), International Encyclopedia of the Social \& Behavioral Sciences, (p. 25). Amsterdam, Netherlands: Elsevier. https://doi.org/10.1016/B978-0-08-097086-8.24030-0

Park, E., Kim, K. J., \& Kwon, S. J. (2017). Corporate social responsibility as a determinant of consumer loyalty: An examination of ethical standard, satisfaction, and trust. Journal of Business Research, 76, 8-13. https://doi.org/10.1016/j.jbusres.2017.02.017

Park, N., \& Peterson, C. (2006). Moral competence and character strengths among adolescents: The development and validation of the Values in Action Inventory of Strengths for Youth. Journal of Adolescence, 29(6), 891-909. https://doi.org/10.1016/j.adolescence.2006.04.011

Robinson-Wood, T. (2016). The convergence of race, ethnicity, and gender: Multiple identities in counseling. Thousand Oaks, CA: Sage Publications.

Rokeach, M. (1973). The nature of human values. New York, NY: John Wiley.

Rosenthal, D. (1955). Changes in some moral values following psychotherapy. Journal of Consulting Psychology, 19(6), 431-436. https://doi.org/10.1037/h0045777

Schwartz, S. H. (2017). The refined theory of basic values. In S. Roccas \& L. Sagiv (eds.), Values and Behavior. Cham: Springer. https://doi.org/10.1007/978-3-319-56352-7_3

Schwartz, S. H., \& Bilsky, W. (1987). Toward a universal psychological structure of human values. Journal of Personality and Social Psychology, 53(3), 550-562. https://doi.org/10.1037/0022-3514.53.3.550

Schwehn, J., \& Schau, C.G. (1990). Psychotherapy as a process of value stabilization. Counseling and Values, 35(1). 24-30. https://doi.org/10.1002/j.2161-007X.1990.tb00355.x

Seligman, C., \& Katz, A. N. (1996). The dynamics of value systems. In C. Seligman, J. M. Olson, \& M. P. Zanna (Eds.), The psychology of values: The Ontario symposium (pp. 53-75). Mahwah, NJ: Lawrence Erlbaum Associates, Inc.

Sheth, J. N., Newman, B. I., \& Gross, B. L. (1991). Why we buy what we buy: A theory of consumption values. Journal of Business Research, 22(2), 159-170. https://doi.org/10.1016/0148-2963(91)90050-8

Smith, C., \& Sikkink, D. (2003). Social predictors of retention in and switching from the religious faith of family of origin: Another look using religious tradition self-identification. Review of Religious Research, 45(2), 188-206. https://doi.org/10.2307/3512582

Smith, B., Vicuna, B., \& Emmanuel-Aviña, G. (2015). Spiritual development and calling. J. Wade, L. Marks, \& R. Hetzel (Eds.), Positive psychology on the college campus. New York, NY: Oxford University Press.

Stern, P. C. (2000). New environmental theories: Toward a coherent theory of environmentally significant behavior. Journal of Social Issues, 56(3), 407-424. https://doi.org/10.1111/0022-4537.00175

Sugrue, L. P., Corrado, G. S., \& Newsome, W. T. (2004). Matching behavior and the representation of value in the parietal cortex. Science, 304(5678), 1782-1787. https://doi.org/10.1126/science.1094765

Tjeltveit, A. C. (1986). The ethics of value conversion in psychotherapy: Appropriate and inappropriate therapist influence on client values. Clinical Psychology Review, 6(6), 515-537. https://doi.org/10.1016/0272-7358(86)90035-8 